\title{
Crafting the Brain - Role of Histone Acetyltransferases in Neural Development and Disease
}

\author{
Bilal N. Sheikh ${ }^{1,2}$ \\ ${ }^{1}$ Division of Development and Cancer, The Walter and Eliza Hall Institute of Medical Research, \\ Melbourne 3052, Victoria, Australia \\ ${ }^{2}$ Department of Medical Biology, University of Melbourne, Melbourne 3052, Victoria, Australia
}

Running title: HATs in Neural Development

Corresponding author:

Bilal N. Sheikh, 1G Royal Parade, Melbourne 3052, Victoria, Australia, e-mail: sheikh@wehi.edu.au Ph: +61 393452538 Fax: +61 393470852

Key words: epigenetics, chromatin, KAT, Querkopf, TIP60 


\begin{abstract}
The human brain is a highly specialized organ containing nearly 170 billion cells with specific functions. Development of the brain requires adequate proliferation, proper cell migration, differentiation, and maturation of progenitors. This is in turn dependent on spatial and temporal coordination of gene transcription, which requires the integration of both cell intrinsic and environmental factors. Histone acetyltransferases (HATs) are one family of proteins that modulate expression levels of genes in a space and time dependent manner. HATs and their molecular complexes are able to integrate multiple molecular inputs, and mediate transcriptional levels by acetylating histone proteins. In mammals, nineteen HATs have been described, and are separated into five families (p300/CBP, MYST, GNAT, NCOA, and transcription-related HATs). During embryogenesis, individual HATs are expressed or activated at specific times and locations to coordinate proper development. Not surprisingly, mutations in HATs lead to severe developmental abnormalities in the nervous system and increased neurodegeneration. This review focuses on our current understanding of HATs and their biological roles during neural development.
\end{abstract}

\title{
Introduction
}

The human brain contains around 85 billion neurons and a similar number of glial cells (Azevedo et al. 2009). Neurons and glial cells contain many specialized subtypes, and neurons can form thousands of short and long distance connections with other cells to process and transfer information. The seed for neural-lineage development is sowed during gastrulation, whereby the embryonic ectoderm, one of the three germ layers, gives rise to the entire central nervous system (Gilbert 2003, Stiles and Jernigan 2010). Starting from a small population of neural-lineage restricted stem cells, neural progenitors undergo a large number of divisions, migrate to their correct locations, differentiate into specialized cell types depending on their locality, and form connections with other cells via synapses. Thus, it is not surprising that proper neural development requires very precise temporal and spatial expression of a large number of genes, and perturbations in these processes lead to disorders such as intellectual disability and neurodegeneration. While genetics play an important role during neural development, a number of environmental and activity-dependent signals that modulate 
cell proliferation, maturation and cell survival, are also important mediators of proper neural development. One key mechanism regulating precise gene expression is chromatin structure, which can integrate both cell intrinsic and environmental information to induce specific phenotypic outcomes (Berger 2007, Feil and Fraga 2011, Jaenisch and Bird 2003, Kouzarides 2007).

Eukaryotic cells organize their genomic material into chromatin, which consists of both DNA and DNA-associated proteins such as histones. The basic repeating unit of chromatin is the nucleosome, which was first proposed by Kornberg in 1974 (Kornberg 1974). Each nucleosome contains approximately $146 \mathrm{bp}$ of DNA, combined with a histone octomer - two each of histone H2A, H2B, H3 and H4. The high-resolution crystal structure of the nucleosome revealed that the histone proteins are closely associated with DNA (Luger et al. 1997). Through hydrogen bonds, approximately 116 direct interactions exist between DNA and histone proteins in each nucleosome (Davey et al. 2002). In addition, N-terminal tails of histones protrude out of the nucleosomal core and are subject to post-translational modifications. Approximately 130 different post-translational histone modifications have been described (Tan et al. 2011). These modifications include acetylation (ac), methylation (me), ubiquitination (ub), phosphorylation (p) and sumoylation (su) (Bannister and Kouzarides 2011). Histone modifications have three potential effects. (1) Post-translational modifications of histones can modify the interaction between DNA and histones. For instance, nonacetylated histone $\mathrm{H} 4$ tail has a much higher specificity for double stranded DNA, compared to acetylated H4 (Hong et al. 1993). Addition of the acetyl-group to histone lysine residues neutralizes the positive charge of lysine amino acids, and thereby retards histone interactions with the negatively charged DNA backbone. (2) Histone modifications can act as sites to recruit molecular complexes. Examples include methylated lysine residues, which are bound by chromodomains, and acetylated lysine residues, which form binding sites for bromodomains. Chromodomains, bromodomains, and other domains with preferences for different histone modifications are common features of molecular complexes that associate with chromatin (reviewed by Lee and Workman 2007, Taverna et al. 2007). Thus, histone modifications may serve as a combinatorial code that is read by specific transcriptional complexes, as proposed by the 'histone code' hypothesis (Strahl and Allis 2000). (3) Histone modifications can alter nucleosome-nucleosome interactions and thereby change overall chromatin 
structure. Acetylated histones for instance, inhibit higher-order folding of nucleosomes in extra-cellular nucleosome arrays and allow enhanced transcriptional activity (GarciaRamirez et al. 1995, Tse et al. 1998).

One of the most common post-translational modifications of histones is acetylation. Histone acetylation is linked to a transcriptionally active chromatin state (Sterner and Berger 2000). An important attribute of histone acetylation is that it is reversible. Histone acetyltransferases (HATs) catalyze the transfer of an acetyl group from Acetyl coenzyme A to $\varepsilon$-amino group of lysine residues, while histone deacytlases (HDACs) remove the acetyl group. Importantly, HATs can also catalyze the acetylation of a large number of non-histone proteins (Choudhary et al. 2009), leading to HATs becoming more broadly known as lysine acetyltransferases (KATs) (Allis et al. 2007). This, along with the continuous identification of proteins with HAT activity, lead Allis et al. (2007) to propose a new nomenclature for HATs with the prefix 'KAT'. While some reports have now starting using the nomenclature proposed by Allis et al. (2007), numerous reports continue to use historical names. This review will use the most common name for each HAT, which sometimes varies between different species, while defining the associated KAT nomenclature when each HAT family is introduced.

Nineteen HATs have been identified in mammals (Voss and Thomas 2011), and are organized into five families based on their domain structure and sequence homology (Figure 1) (Marmorstein and Roth 2001, Sterner and Berger 2000). These include the p300/CBP family, MYST-family, the GCN5-related HAT (GNAT) superfamily, the nuclear receptor co-activator (NCOA) family, and a set of transcription-initiationrelated factors. The activity of HATs is opposed by HDACs. In both mice and humans, eighteen proteins with HDAC activity have been identified, and are divided into four classes (Haberland et al. 2009, North and Verdin 2004). Interestingly, both HATs and HDACs are present at transcriptionally active genes. Wang and co-workers used chromatin immunoprecipitation (ChIP) and deep sequencing in human $\mathrm{CD} 4^{+} \mathrm{T}$-cells to show that HATs CBP, p300, PCAF, MOF and TIP60, along with HDACs HDAC1, HDAC2, HDAC3 and HDAC6, are all present at transcriptionally active and not transcriptionally silent gene loci (Wang et al. 2009). This suggests that histone acetylation and deacetylation are dynamic processes that occur during gene transcription. 
With the progress of new technologies and analysis of mouse knockout models over the past decade, great advances have been made in our understanding of histone acetylation during important biological processes. This review will discuss what is currently known about the activity of HATs during embryonic development, with a particular focus on neural development. Perturbations in HAT activity leading to neural disorders will also be highlighted. Given that the function of HDACs has been extensively reviewed recently (de Ruijter et al. 2003, Haberland et al. 2009, Hayakawa and Nakayama 2011, Lilja et al. 2013, Yao and Yang 2011), they will not be discussed here. For an in-depth description of neural development, readers are referred to the following excellent reviews and textbooks (Gilbert 2003, Gotz and Huttner 2005, Greene and Copp 2009, Price et al. 2011, Stiles and Jernigan 2010). Reviews focusing on the roles of other chromatin modifications in neural development can be found in this special edition of Cell and Tissue Research.

\section{Key roles for HATs in neural development}

HATs have unique functions, which are partly due to (1) the specificity of their catalytic activity towards different histone lysine residues, (2) HAT activity directed towards specific or all gene loci, (3) their spatial and temporal expression pattern, and (4) their specific recruitment by other molecular complexes to chromatin. For instance, the MYST-family member MOF specifically acetylates H4K16 (Gupta et al. 2008, Thomas et al. 2008), while HBO1 specifically acetylates H3K14 in mice (Kueh et al. 2011). In addition, HATs can either acetylate genome-wide, or at specific gene loci. In cultured Mof ${ }^{\%}$ blastocysts, no nuclear H4K16ac is observed (Thomas et al. 2006), while depletion of its family member $\mathrm{Moz}$, does not affect global H3K9ac, but rather reduces H3K9ac at specific target genes in vivo, namely Hox, Tbxl and Tbx5 gene loci (Voss et al. 2009, Voss et al. 2012). Furthermore, HATs can show a very specific spatial and temporal expression pattern. For example, the HAT p300 is strongly expressed at mouse embryonic day (E) 8.5, particularly in the neural folds and somites. In contrast, by E9.5, p300 expression is confined to the first two branchial arches, the limb buds and caudal somites (Bhattacherjee et al. 2009). As suggested by these examples, individual HATs have unique functions, which are only partly shared by other HATs. Therefore, the 
function of each HAT is discussed separately, with a particular emphasis on the role of HATs during neural development.

\section{p300/CBP-family}

This family is named after its two mammalian members - p300 (KAT3B) and CREB binding protein (CBP, KAT3A), which are two of the most highly studied HATs. p300 was identified as a protein that binds to adenovirus protein E1A, whereby E1A inhibits the transcription-activating properties of p300 at the SV40 promoter (Eckner et al. 1994). CBP was discovered due to its interaction with the phosphorylated form of CREB (Chrivia et al. 1993). p300 and CBP are highly similar proteins and share an identical domain structure (Figure 1). Within the HAT and KIX domains, p300 and CBP are 86\% identical at the amino acid level (Chan and La Thangue 2001). In cell-free and over-expression assays, both p300 and CBP bind to a similar set of over forty transcription factors including ETS-1 (Yang et al. 1998), c-MYB (Oelgeschlager et al. 1996), CREB (Lundblad et al. 1995), and STAT2 (Bhattacharya et al. 1996), and are able to stimulate transcription of their target genes. p300 and CBP have been implicated in processes as diverse as cell cycle regulation, apoptosis, embryonic development, cellular differentiation and cancer (reviewed by Chan and La Thangue 2001, Goodman and Smolik 2000, Kalkhoven 2004). However, whether p300 and CBP interact with these transcription factors in vivo, and the importance of these interactions in a biological context is not fully understood. For instance, over-expressed p300 and CBP both bind to CREB and c-MYB in vitro and stimulate transcription at their target genes (Lundblad et al. 1995, Oelgeschlager et al. 1996). However, mice with point mutations in the CREB- and c-MYB-binding KIX domain of CBP are relatively normal, while the same point mutations in p300 leads to a severe reduction in the number of mature hematopoietic cells (Kasper et al. 2002). Hence, not all p300/CBP interactions observed in vitro are likely to be biologically relevant in vivo.

A number of mouse models of $p 300$ and $C b p$ have been described. Mice deficient in p300 (Yao et al. 1998), Cbp (Tanaka et al. 2000), or knock-in mice expressing a truncated version of CBP lacking the HAT domain (Oike et al. 1999b), growth arrest between E9.5 and E11.5. The neural tube in both $p 300$ and $C b p$ mutant mice fails to close. Consistently, $p 300$ and $\mathrm{Cbp}$ are strongly expressed along the neural tube at E8.5, 
particularly in the dorsal portion of the neural tube (Bhattacherjee et al. 2009, Oike et al. 1999b). The molecular mechanism underlying the failure of neural tube closure in $p 300$ and $C b p$ mutant mice remains to be determined. Extrapolating from the recent work of Visel et al. (2009), who identified over 2,500 genomic binding sites for p300 in the E11.5 forebrain, there are likely to be a large number of p300 and CBP targets during neural development. In addition to the neural tube phenotype, $p 300^{-/-}$embryos show a decrease in the density of mesenchymal cells at E10.5, and fibroblasts isolated from $p 300^{-/}$embryos show premature growth arrest after three to four divisions (Yao et al. 1998). A number of cardiac defects with variable penetrance have also been reported in the $p 300^{-/}$mice. In comparison to $p 300^{-/-}$embryos, $\mathrm{Cbp}^{-{ }^{--}}$mutants show hemorrhaging in both the telencephalon and mesencephalon, and a decrease in mesenchymal cells, which are also highly disorganized (Tanaka et al. 2000). No cardiac defects have been reported in $\mathrm{Cbp}^{-/}$embryos. Reduction in vascularization, along with a decrease in the number of erythrocytes and primitive hematopoietic progenitors is evident in $\mathrm{Cbp}^{-/-}$yolk sacs and embryos at E9.5 and E10.5 (Oike et al. 1999b, Tanaka et al. 2000). Intriguingly, $\mathrm{p} 3 \mathrm{O}^{+/-} ; \mathrm{Cbp}^{+/-}$double heterozygous mice also exhibit open neural tubes and exencephaly, and growth arrest between E9.5 and E11.5 (Yao et al. 1998). This suggests that while p300 and CBP cannot compensate for each other in loss-of-function mutants, they do act synergistically in a number of biological processes, and embryonic development is critically dependent on the dose of p300 and CBP. Together, these reports identify p300 and CBP as essential regulators of embryonic development, and in particular, neural development.

In humans, heterozygous mutations in both CBP (Petrij et al. 1995) and p300 (Roelfsema et al. 2005) have been described in individuals diagnosed with the Rubinstein-Taybi syndrome (RTS). RTS is prevalent in 1:125,000 live births and is characterized by severe intellectual disability, prominent broad thumbs and big toes and striking facial abnormalities (reviewed by Roelfsema and Peters 2007). A variety of cardiac defects are evident in approximately one-third of RTS patients. Furthermore, RTS patients are more prone to a range of malignancies originating from neural cells (Miller and Rubinstein 1995). Interestingly, mutations in CBP leading to RTS are approximately 20-fold more common than mutations in p300 (Roelfsema and Peters 2007). 
Given the direct link between mutations in $p 300$ and $C B P$ leading to RTS, a number of studies have modeled RTS using $p 300^{+/-}$and $\mathrm{Cbp}^{+/-}$mice. In the $p 300^{+/-}$model, $75 \%$ of mice present craniofacial abnormalities including a prominent forehead and a blunt nose (Viosca et al. 2010). Similar to delayed postnatal growth in RTS patients, adult $p 300^{+/-}$ mice show a $13 \%$ decrease in body weight, and $p 300^{+/-}$mice exhibit slower movement. Two different heterozygous mutations in $C b p$ have been studied as a model of RTS. Tanaka and co-workers (1997) have described RTS-like symptoms at low penetrance in $\mathrm{Cbp}^{+/}$mice, while Oike and co-workers (1999) have described higher penetrance of RTS-like symptoms in mice expressing a dominant-negative version of CBP (CBP $\Delta$ ), which contains only the first 1084 amino acids and not the HAT domain of CBP. In the $\mathrm{Cbp}^{+/-}$model, delayed ossification of the skull (in $100 \%$ of $\mathrm{Cbp}^{+/-}$mice), an enlarged anterior frontaneal (66\%), and defects in the sternum (33\%) are observed (Tanaka et al. 1997). Limb deformities are rare, while cardiac defects have not been reported. In contrast, in the heterozygous $C b p^{\Delta /+}$ model, stunted growth, delayed ossification, broad nasal ridge, short nose, and underdeveloped maxilla are evident in all mutant mice (Oike et al. 1999a). In addition, $16.6 \%$ of E19.5 $\mathrm{Cbp}^{\Delta /+}$ mice display cardiac anomalies, with ventricular septal defects being the most common. The differences between the two $C b p$ models are difficult to reconcile, but it is interesting to speculate that the truncated CBP $\triangle$ may be able to bind some transcription factors and signaling molecules, and thereby restrict their availability for other functions. Furthermore, CBP $\Delta$ may also be able to bind to chromatin targets and thereby restrict the ability of p300 to compensate for its loss. Curiously, the broad thumbs and big toes common in RTS patients are not observed in the $p 300$ or $C b p$ mouse models. Furthermore, no gross morphological changes have been observed in $\mathrm{p} 300^{+/-}$or $\mathrm{Cbp}^{\Delta /+}$ brains (Oike et al. 1999a, Viosca et al. 2010), suggesting that heterozygousity for $p 300$ or $C b p$ may result in subtle molecular defects that underlie the intellectual disability phenotype observed in RTS patients.

The intellectual disability evident in RTS patients has been difficult to phenocopy in mouse models. To investigate intelligence in mouse models of RTS, studies have attempted to analyze learning behaviors and memory retention. Mouse models including (1) $\mathrm{Cbp}^{+/-}$(Alarcon et al. 2004), (2) $p 300^{+/-}$(Viosca et al. 2010), (3) $C b p^{\Delta /+}$ (Oike et al. 1999a), and conditional transgenics specifically expressing either (4) dominant negative CBP (amino acids 1-1084, Wood et al. 2005) or (5) CBP with point mutations in the 
HAT domain (Korzus et al. 2004) in mature neurons (driven by CaMKII $\alpha$ ), showed variable results in memory and learning. While all five studies showed that short-term memory in $p 300$ or $C b p$ mutants was unaffected, long-term memory was found to be deficient. However, different tests such as the Morris water maze, fear conditioning and object recognition tasks produced different results in different studies (summarized by Josselyn 2005). Nevertheless, each study showed that $p 300$ and $C b p$ mutant mice were deficient in at least one long-term memory retention test. It is interesting to note the lack of morphological defects in $p 300^{+/-}$(Viosca et al. 2010) and $C b p^{\Delta /+}$ adult brains (Oike et al. 1999a), despite memory retention defects. This would suggest that $p 300$ and $C b p$ are more important postnatally than during development with regards to intellectual disability in RTS patients. However, one must keep in mind that epigenetic regulation is also highly dependent on environmental influences, which would be difficult to include in any mouse model of intelligence where epigenetic regulators such as p300 or CBP are involved.

While adult p300 and Cbp mutant brains are normal, a detailed study by Wang et al. (2010) has identified defects during development of $C b p^{+/-}$mice, which are not present in adults. In cortical cultures from E11.5-E12.5 embryos with reduced $C b p$ mRNA (using $\mathrm{Cbp}^{+-}$mice or siRNA knockdown of $C b p$ ), no differences in cell proliferation or apoptosis are observed (Wang et al. 2010). However, upon differentiation, a reduction in major cell types, namely neurons, astrocytes, and oligodendrocytes is evident in $\mathrm{Cbp}$ deficient cultures. Similar results were observed in vivo, when $C b p$ siRNA was electroporated into embryos in utero at E13 or E14. At postnatal day (PN) 3 in these mice, a reduction in neurons, astrocytes and oligodendrocytes was found. Strikingly, the researchers found no defects in adult mice, at least in the corpus callosum of adult mice, which showed fewer GFAP-positive glial cells at PN10. The defects in differentiation of $\mathrm{Cbp}^{+/-}$neural precursors were associated with reduced CBP binding at promoters of genes active in differentiated neurons, astrocytes, and oligodendrocytes, and a concomitant decrease in $\mathrm{H} 3 \mathrm{~K} 9 / 14$ acetylation (Wang et al. 2010). However, it is difficult to ascertain whether the decrease in $\mathrm{H} 3 \mathrm{~K} 9 / 14$ acetylation levels in Cbpdeficient cells are due to decreased transcription at these loci, or whether they are the direct targets of CBP HAT activity. For instance, CBP shows lower preference for acetylating $\mathrm{H} 3 \mathrm{~K} 9$ and $\mathrm{H} 3 \mathrm{~K} 14$ in cell free assays compared to other lysine residues on histone H3 and H4 tails (Henry et al. 2013). Furthermore, null deletion of p300 and Cbp 
in immortalized MEFs results in a global reduction of H3K18 and H3K27 acetylation, but not H3K4, H3K9, H3K14, H3K32, H3K36, H3K56, H4K5, H4K8, H4K12, or H4K16 acetylation (Jin et al. 2011). Nevertheless, work from Wang et al. (2010) suggests that the intellectual disabilities observed in RTS patients may in part be due to delayed development of the brain, in combination with defects in long-term memory and learning in the postnatal brain described above. In comparison to CBP, a ChIP-seq. study by Visel and co-workers described 2543 genomic binding sites for p300 in the E11.5 forebrain. Interestingly, p300 binding was reported to be greatest at genomic enhancers near genes that are most highly expressed in the forebrain (Visel et al. 2009). Indeed, p300 binding is also highly enriched at enhancers in HeLa cells, which are marked by H3K4me1 and show DNase I hypersensitivity (Heintzman et al. 2007). Whether a lack of p300 at genomic enhancers leads to impaired differentiation in a manner similar to the $\mathrm{Cbp}^{+/-}$model remains to be determined. One indication that $\mathrm{p} 300$ may act in this manner is that over-expression of p300 in neuroepithelial cells leads to increased promoter activity of the astrocyte-specific marker GFAP, suggesting that p300 may promote astrocytic differentiation (Nakashima et al. 1999).

p300 and CBP are central to a number of pathways and biological processes. Recent in vivo studies suggest that p300 and CBP are particularly important for activating gene expression programs when multipotent cells are induced to differentiate into mature lineages normally found in the brain (Lee et al. 2009, Visel et al. 2009, Wang et al. 2010). In future, studies correlating the genomic binding of endogenous p300 and CBP, to changes in gene expression and phenotype will continue to provide important insights into their functions. Importantly, the potential use of HDAC inhibitors, which have been shown to alleviate both developmental (Wang et al. 2010) and memory-related disorders in $\mathrm{Cbp}^{+/-}$mice (Alarcon et al. 2004), should be further investigated as a possible avenue to ease some symptoms in RTS patients.

\section{MYST-family}

The MYST family of HATs, named after its founding members, $\underline{\mathrm{MOZ}}$, bff2/sas3, sas2, and tip60, consists of five members in both humans and Mus musculus (Figure 1): (1) Monocytic leukemia zinc finger (MOZ, MYST3, KAT6A), (2) Querkopf (QKF, MYST4, MORF, KAT6B), (3) Histone acetyltransferase bound to ORC (HBO1, 
MYST2, KAT7), (4) Male absent on the first (MOF, MYST1, KAT8), and (5) the 60 $\mathrm{kDa}$ Tat-interactive protein (TIP60, KAT5) (Thomas and Voss 2007). This family is characterized by the presence of the highly conserved MYST catalytic domain (Voss and Thomas 2009). While the MYST family is the largest family of HATs, it is also the least studied. Nevertheless, the MYST family has drawn a lot of attention over the past five years, leading to a rapid expansion in our knowledge of this diverse family.

\section{Querkopf}

$Q k f$ was identified in a mouse genetrap screen for genes important in neural development, and purified QKF was found to primarily acetylate free histones $\mathrm{H} 3$ and H4 (Champagne et al. 1999, Pelletier et al. 2003, Thomas et al. 2000). The human homolog of QKF, KAT6B (also commonly referred to as MYST4 or MORF in human), has been identified as the catalytic unit of the human ING5 complex (Doyon et al. 2006). However, family members MOZ and HBO1 have also reported to be in the ING5 complex in place of KAT6B, suggesting that some level of redundancy may exist amongst members of the MYST family (Doyon et al. 2006).

In the mouse, $Q k f$ is highly expressed in the neurogenic regions of both the developing (Thomas et al. 2000), and the adult brain (Merson et al. 2006), suggesting that it plays an important role during neurogenesis. Indeed, in $Q k f$-genetrap mutant mice, there is a reduction in the size of the telencephalon at E11.5, and in the size of the cortical plate at E13.5, E15.5 and E17.5 (Thomas et al. 2000). The authors correlated this with a decrease in cell number in these tissues. Consistently, a reduction in the size of the cerebral cortex, but not the cerebellum, is observed in adult $Q k f$-mutant mice. In addition, $Q k f$-mutant brains show a decrease in layer V pyramidal cells, and a $39 \%$ decrease in GAD67-postive GABAergic interneurons (Thomas et al. 2000). In the adult brain, regions of high $Q k f$ expression are confined to the neurogenic regions, namely the subventricular zone (SVZ) and the hippocampus. Neural stem cells (NSCs) residing in the SVZ generate neural progenitors (neuroblasts) that migrate to the olfactory bulb and differentiate into olfactory interneurons (Lois et al. 1996). This process is considered particularly important for olfactory memory (Rochefort et al. 2002). In contrast, NSCs residing in the hippocampus are thought to be important for laying down new memories, in particular spatial memories (Imayoshi et al. 2008, Zhang et al. 2008). At least in the SVZ, the highest expression of $Q k f$ is confined to self-renewing and 
multipotent stem cells (Sheikh et al. 2012). Consistently, fewer colonies of neural progenitors and stem cells, referred to as neurospheres, are generated from the SVZ of Qkf-mutant mice, indicating a role for QKF in maintaining NSCs in vivo (Merson et al. 2006). Indeed, $Q k f$-mutant mice display an age-related decline in the generation of neuroblasts, and consequently, a decrease in the size of olfactory bulbs (Merson et al. 2006). Interestingly, HAT activity of the Drosophila homologue of QKF and MOZ, Enok, is essential for the proliferation of neuroblasts and the correct formation of mushroom bodies, which are required for olfactory learning and memory in Drosophila (Scott et al. 2001). This suggests that enok and $Q k f$ share a conserved biological role across two very different species. A role for QKF has also been identified during neuronal differentiation. When $Q k f$-deficient neurospheres are induced to differentiate, they form fewer neurons. In contrast, over-expression of $Q k f$ leads to an increase in the formation of neurons (Merson et al. 2006). Consistently, only neurosphere colonies generated from SVZ cells expressing high levels of $Q k f$ are able to give rise to the three major neural lineages - neurons, astrocytes, and oligodendrocytes (Sheikh et al. 2012). Neurospheres generated from SVZ cells expressing low levels of $Q k f$ are only able to form astrocytes. Together, these studies establish QKF as a key regulator of NSC selfrenewal, multipotency and neuron-lineage differentiation. Further roles for QKF in the regulation of neural cells and systems remain to be established. For instance, the role of $Q k f$ in regulating neurogenesis in the hippocampus is yet to be explored. While QKF has been shown to have HAT activity in cell free assays (Pelletier et al. 2003), the exact histone targets of QKF in vivo remain to be established. Given that QKF is a HAT, it is likely to activate gene transcription. These gene targets remain to be identified.

A number of recent studies have reported mutations in the human homolog of $Q k f$, $K A T 6 B$. Kraft and co-workers reported a heterozygous translocation involving $K A T 6 B$, which results in a $50 \%$ reduction in $K A T 6 B$ mRNA expression levels, and leads to clinical features that are similar to Noonan syndrome (Kraft et al. 2011). Consistent with a $50 \%$ reduction in $K A T 6 B$ mRNA, a $40 \%$ reduction of acetylation activity at histone $\mathrm{H} 3$ is observed. Although only one functional copy of KAT6B was defective, this patient with Noonan-like syndrome presented with short stature, low body weight, intellectual disability, bone defects, and craniofacial defects. These symptoms are remarkably similar to the phenotype observed in $Q k f$-deficient mice (Thomas et al. 2000). 
Two separate groups have described heterozygous mutations localized to the C-terminal acidic domain of $K A T 6 B$, which lead to truncations of KAT6B, and clinical features of Genitopatellar syndrome (GPS) (Campeau et al. 2012, Simpson et al. 2012). GPS patients present with a combination of patellar aplasia, genital abnormalities, craniofacial defects including micognathia and a broad/bulbous nose, intellectual disability, and corpus callosum agenesis. In GPS patients, the truncated KAT6B message is present at normal levels (Campeau et al. 2012, Simpson et al. 2012). However, a reduction in $\mathrm{H} 3$ and $\mathrm{H} 4$ acetylation is evident in skin fibroblast lines derived from patients (Simpson et al. 2012). Despite the features of GPS largely affecting the same tissues as $Q k f$ hypomorphic mice (Thomas et al. 2000), these clinical features are distinct from the $Q k f$ phenotype and that of Noonan-like syndrome (Campeau et al. 2012). This may be attributed to the intact N-terminal and MYST catalytic domain in GPS patients, with a loss of the serine and methionine rich domains, which may lead to decreased catalytic activity of the KAT6B complex. Indeed, the serine and methionine rich domains of QKF have been shown to interact with RUNX1 and RUNX2 and stimulate transcription at RUNX1 and RUNX2 target genes (Pelletier et al. 2002). Similarly, truncations in $K A T 6 B$ at the level of the methionine rich domain have been identified in 11 out 12 patients presenting with typical features of the Say-BarberBiesecker-Young-Simpson syndrome (SBBYSS), which is a variant of Ohdo syndrome (Clayton-Smith et al. 2011). KAT6B truncations found in SBBYSS are further towards the C-terminus of KAT6B compared to truncations in GPS. SBBYSS patients present with a subset of craniofacial defects including expressionless face, small mouth and bulbous nose, as well as intellectually disability, joint laxity, abnormally long thumbs, blepharophimosis, cardiac defects, and hypoplastic patellae. While there is some overlap in symptoms of SBBYSS and GPS, a number of features such as genital and renal defects are unique to GPS. This suggests that the C-terminal serine and methionine rich domains of KAT6B have a very important role in regulating the activity of the KAT6B complex, probably by mediating interactions with other transcription factors. In future, it will be of interest to determine what other transcription factors KAT6B interacts with to regulate neural and craniofacial development. 
Tip60

TIP60 (KAT5) was first identified in a human B-lyphoblastoid cell line, due to its strong association with the human immunodeficiency virus (HIV)-1 protein Tat1 (Kamine et al. 1996). In mammalian cell lines, TIP60 has been widely studied. A central role for TIP60 has been established in double stranded DNA break repair, cell proliferation, apoptosis and cancer (reviewed by Sapountzi et al. 2006, Squatrito et al. 2006, Sun et al. 2010, Szumiel and Foray 2011). In the mouse, mice lacking Tip60 die at the blastocyst stage. Tip60 $60^{-/}$blastocysts fail to hatch and Tip60 ${ }^{-/-}$inner cell mass cells are unable to proliferate (Hu et al. 2009). Similarly, when the Drosophila Tip60 protein (dTip60) is ubiquitously knocked down using RNAi, the mutant Drosophila flies do not develop past the early pupal stage (Zhu et al. 2007). Most cellular TIP60 forms part of a 14-protein complex including inhibitor of growth (ING) 3 in human MCF-7 and HeLa cells (Doyon et al. 2004). However, proteins external to the TIP60-ING3 complex are also known to interact with TIP60 (Sapountzi et al. 2006). TIP60 associates with the intracellular portion of the amyloid precursor protein (APP) and Fe65, and over expression of TIP60, APP and Fe65 together stimulates transcription in human cancer cell lines (Cao and Sudhof 2001). APP is a plasma membrane-bound protein that is cleaved by $\alpha$-, $\beta$ - and $\gamma$ - secretases to give rise to both an intracellular and extracellular portion, with the extracellular portion giving rise to $\beta$-amyloids fibers that are central to the pathophysiology of Alzheimer's disease (Nunan and Small 2000). Through its interaction with APP, TIP60 is thought to play an important role in the physiology of Alzheimer's disease, primarily by regulating gene expression.

The role of Tip60 in the nervous system has been extensively studied in the Drosophila system. When a dominant negative form of dTip60, which lacks HAT activity, is specifically expressed in the nervous system using a 179-Gal4 driver, lethality is observed at the late $3^{\text {rd }}$ instar stage (Pirooznia et al. 2012b). Similarly, over-expression of the human APP in the Drosophila nervous system also leads to early lethality. Strikingly, the early lethality observed in Drosophila over-expressing the human APP in the nervous system can be partially rescued by the over-expression of wild type dTip60 in the same flies (Pirooznia et al. 2012b). In contrast to the Drosophila model, TIP60 is essential for the induction of cell death mediated by over-expression of the intracellular C-terminal portion of APP in human H4 neuroglioma cells (Kinoshita et al. 2002). The 
contrasting results from these studies could be due to different experimental approaches, in particular utilizing human cancer cell lines versus the in vivo Drosophila model. More recently, other features of Alzheimer's disease have also been identified in Drosophila models lacking the HAT activity of dTip60. When Tip60 is specifically knocked down in ventrolateral neurons in vivo, an area that regulates circadian rhythms in Drosophila, synaptic regression is evident in the small verolateral neurons (Pirooznia et al. 2012a). This synaptic regression is associated with changes in sleeping patterns of Drosophila, with decreased night sleep and an increase in daytime sleep (Pirooznia et al. 2012a), which is reminiscent of patients suffering from neurodegenerative diseases (Chokroverty 2009). Furthermore, Tip60 knockdown in the nervous system of Drosophila leads to slow sluggish movement in the affect larvae, underpinned by defects in axonal transport in motor neurons (Johnson et al. 2013). Interestingly, similar locomotion and axonal transport defects are observed when human APP is overexpressed in the Drosophila nervous system, and these defects can be rescued by the over-expression of wild type dTip60 (Johnson et al. 2013). Hence, it appears that dTip60 has a protective effect over neurodegenerative disease, at least in the context of Alzheimer's disease.

The function of mammalian TIP60 during neural development has been difficult to ascertain. This is primarily due to a range of important roles in regulating cell proliferation, apoptosis and homeostasis attributed to TIP60. However, in mouse PN4 retinas, endogenous TIP60 has been shown to immunoprecipitate with the transcription factor PAX6, and over-expression of TIP60 is able to potentiate the transcriptional activity of PAX6 in a luciferase assay (Kim et al. 2012). Given the importance of Pax6 in neural development (reviewed by Georgala et al. 2011), it would be valuable to determine whether TIP60 is important for the transcriptional activation by PAX6 in other parts of the nervous system, especially during development. Furthermore, studies of TIP60 in a wild type context will be beneficial. For instance, ChIP experiments utilizing TIP60 antibodies on mammalian nervous system tissue, which does not have impairments in cellular homeostasis, would be highly insightful.

\section{Mof, Hbol and Moz}

Little is known about the roles of MOF, HBO1 and MOZ during neural development, in part due to the early embryonic lethality of homozygous mutants. Mof ${ }^{-/-}$die at E4.5, 
shortly after blastocyst implantation, show extensive apoptosis, and the inner cell mass from E3.5 $\mathrm{Mof}^{\%}$ blastocysts cultured in vitro is unable to proliferate (Thomas et al. 2008). Mof $^{-/}$embryos lack H4K16 acetylation, a mark associated with active transcription, but are not compromised in acetylation at H3K9, H3K14, H4K5, H4K8, or H4K12 (Gupta et al. 2008, Thomas et al. 2008). Furthermore, requirement for MOF in acetylating H4K16 has been reported in human HeLa and HepG2 cells (Taipale et al. 2005), while purified Drosophila Mof also acetylates H4K16 on free histones and nucleosomes (Akhtar and Becker 2000). Interestingly, the requirement of Mof and H4K16ac in Drosophila is different from mammals. In Drosophila, Mof is required to acetylate H4K16 specifically on the male X-chromosome, as part of the sex-based dosage compensation mechanism (Hilfiker et al. 1997). While one of the two female Xchromosomes is silenced in mammals, in Drosophila, expression of the male $\mathrm{X}$ chromosome is increased two-fold. The Drosophila Mof and H4K16ac essential for this process. Males, but not females, with a point mutation in the mof HAT domain die at the third-instar stage and fail to undergo metamorphosis (Hilfiker et al. 1997).

In contrast to Mof mutant embryos, $\mathrm{Hbol}^{-/-}$mouse embryos growth arrest at the 10somite stage, and show disorganized blood vessels, mesenchyme and somites (Kueh et al. 2011). Using $\mathrm{Hbol}^{-/-}$MEFs, Kueh and co-workers showed that HBO1 specifically acetylates H3K14, and not H3K9, H4K5, H4K8, H4K12 or H4K16 (Kueh et al. 2011). Interestingly, genes important for neural patterning, specifically Sox2, Otx2, Notch1 and $\mathrm{Shh}$, are expressed at low levels in $\mathrm{Hbol}^{-/}$embryos after gastrulation. Whether this down-regulation of neural specific genes affects neural development in Hbol mutant mice remains to be determined.

$M O Z$ was first identified in the recurrent translocation $\mathrm{t}(8 ; 16)(\mathrm{p} 11 ; \mathrm{p} 13)$, which leads to its fusion with another HAT, CBP, in cases of acute myeloid leukemia (Borrow et al. 1996). Depending on the knockout allele and genetic background, Moz homozygous mutants die between E14.5 and E18.5, and lack transplantable hematopoietic stem cells (Katsumoto et al. 2006, Thomas et al. 2006). Furthermore, Moz mutant mice display craniofacial and cardiac defects that mirror the human DiGeorge syndrome (Voss et al. 2012). The molecular mechanism underlying these defects was found to be reduced Tbxl and Tbx5 expression in Moz-deficient mice, with an associated decrease in H3K9ac at these loci. In addition, $M o z^{\Delta / \Delta}$ embryos show anterior homeotic 
transformations in both the axial skeleton and neural tube, linked to a reduction in H3K9ac at Hox loci (Voss et al. 2009). While the role of MOZ in the nervous system has not been studied, Moz mRNA is strongly expressed in neural progenitor cells cultured as neurospheres in vitro, and is highly enriched in the mesencephalon of the E13.5 mouse embryo (Thomas et al. 2006).

While little is known about the role of MOF, HBO1 and MOZ during neural development, a number of observations point to potential roles for these HATs in neurogenesis. Foremost, Mof, $\mathrm{Hbol}$ and $\mathrm{Moz}$ are all expressed in the developing nervous system. Secondly, neural development requires the proper activation of gene expression and MOF, HBO1 and MOZ are important for maintaining chromatin marks associated with active gene transcription. Since Mof, Hbol and Moz mutant mice are all embryonic lethal and show severe abnormalities in non-neural tissues, central nervous system specific knockouts using cre/lox technology will be highly useful for determining the role of $\mathrm{MOF}, \mathrm{HBO} 1$ and $\mathrm{MOZ}$ during neural development.

\section{GNAT superfamily}

The superfamily of GCN5-related N-acetyltransferases (GNAT) includes five HATs (Figure 1). The founding member, General control nonderepressible 5 (GCN5, KAT2A, PACF-B, GCN5L2), is highly similar to the p300/CBP-associated factor (PCAF, KAT2B). Thus, GCN5 and PCAF form a subgroup in this superfamily, and are commonly assigned to their own HAT family. GCN5 and PCAF are 89.5\% identical at the amino acid level in their HAT domains (Voss and Thomas 2011), and both possess the same protein domains (Figure 1). Other members of this superfamily, Cysteine and glycine rich protein 2-binding protein (CSRP2BP, CRP2BP, ATAC2, KAT14), Histone acetyltransferase 1 (HAT1, KAT1), and Elongation protein 3 (ELP3, KAT9), are much more diverse and share little sequence homology with GCN5, PCAF, or with each other (Figure 1). It is thus not surprising that CSRP2BP, HAT1 and ELP3 play very different and specialized roles, which are discussed below.

\section{Gcn5 and Pcaf}

Before identification of GCN5 HAT activity in vertebrates, the homologues of GCN5 in Tetrahymena thermophila and yeast were identified as the first HATs with the ability to 
acetylate free histones (Brownell et al. 1996, Kuo et al. 1996). In contrast, PCAF was first identified as a factor that competes with the adenoviral protein E1A for binding to the C-terminal portion of p300 and CBP (Yang et al. 1996). GCN5 and PCAF have found been identified in two distinct mammalian complexes: (1) the approximately

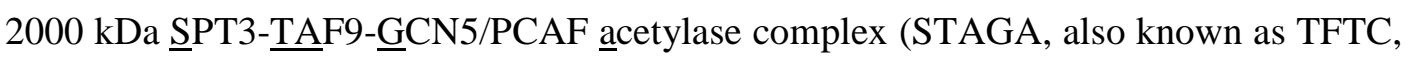
Martinez et al. 1998), and (2) the ADA two-A containing complex (ATAC, Wang et al. 2008). Both the STAGA and ATAC complexes acetylate histone H3 when presented in the form of free histones, or incorporated into nucleosomes (Wang et al. 2008). Consistently, in MEFs lacking both Gcn5 and Pcaf, a specific and global reduction in H3K9 acetylation, but not H3K4, H3K14, H3K18, H3K23, H3K27, H3K36, H3K56, H4K5, H4K8, H4K12, or H4K16 acetylation is observed (Jin et al. 2011).

Two groups have reported knockout mice for Gcn5 and Pcaf. While Pcaf ${ }^{/-}$mice are apparently normal and do not display any phenotypic abnormalities, Gcn $5^{-/-}$mice growth arrest around E9.5, and die by E11.5 (Xu et al. 2000b, Yamauchi et al. 2000). $\mathrm{Gcn5}^{-/-}$embryos show extensive apoptosis and lack mesodermal tissues including somites and head mesenchyme (Xu et al. 2000b). In Pcaf $f^{/-}$animals, it is likely that GCN5 is able to compensate for loss of Pcaf. Consistent with this notion, an elevation in GCN5 protein (Yamauchi et al. 2000), but not Gcn5 mRNA (Xu et al. 2000b), is observed in Pcaf $f^{-}$tissues that normally express high levels of PCAF. Furthermore, $\mathrm{Gcn5}^{-/} ; \mathrm{Pcaf} \mathrm{f}^{/-}$double mutants are growth retarded at E6.5 and arrest at the egg cylinder stage (Xu et al. 2000b). This suggests that PCAF must play an important role at least in early embryonic development. Interestingly, both Gcn5 hypomorphic and Gcn5 mice with no HAT activity, which survive until later in development, show failure in neural tube closure and exencephaly (Bu et al. 2007, Lin et al. 2008b). Despite extensive efforts to identify the morphological and molecular basis for defects in neural tube closure in Gcn5 mutant mice, the underlying cause of exencephaly in these mice remains to be identified. In an attempt to better understand the role of Gcn5 during neural development, Martinez-Cerdeno et al. (2012) made conditional knockouts of Gcn5 using the neural specific Nestin-cre. These conditional Gcn5 mutants show a $26 \%$ decrease in brain mass, and a two-fold decrease in proliferation in the ventricular zone at E12.5 and E17.5, and in the SVZ at E17.5 (Martinez-Cerdeno et al. 2012). Both the ventricular zone and the SVZ contain proliferating progenitor cells that migrate away and differentiate. The decrease in proliferation of progenitors in the Nestin-cre model 
are difficult to reconciled with Gcn5 null mice, which show increased apoptosis and normal proliferation (Xu et al. 2000b). However, it is plausible that GCN5 plays a different role in early embryogenesis compared to neural development, which occurs later in gestation.

The neural tube and the vertebral column develop in parallel and, respectively, give rise to the neural and mesoderm derived structures of the spinal cord. The vertebral column of the mouse consists of seven cervical segments (C) at the most rostral end, followed by thirteen thoracic segments $(\mathrm{T})$ that are attached to ribs, and six lumbar (L) and four sacral (S) segments at the most caudal end. A parallel set of segments is observed along the neural column. The identity of these segments, both in the mesoderm and neural tube, is specified by the spatially and temporally restricted expression of Hox genes in the anterior-posterior axis (Alexander et al. 2009, Forlani et al. 2003). Interestingly, Gcn5 hypomorphic mice that express approximately $30 \%$ of wild type Gcn5 mRNA levels, show anterior homeotic transformations starting with a T12 $\rightarrow$ T10 shift, and subsequently display a L1 $\rightarrow$ T14 transformation with 100\% penetrance (Lin et al. 2008a). Mice deficient in another HAT that acetylates H3K9, the MYST-family member MOZ, show anterior homeotic transformations in both the vertebral column and the neural tube for 19 segments starting at $\mathrm{C} 2 \rightarrow \mathrm{C} 1$, with $\mathrm{L} 1$ being normal (Voss et al. 2009). Hence, it appears that MOZ is required for activating the correct expression of Hox genes in the anterior portion of the embryo (until approximately T13), and GCN5 is required to correctly activate Hox genes in the more posterior portion of the embryo (from approximately T12 onwards). While MOZ has been shown to acetylate H3K9 at Hox loci in vivo (Voss et al. 2009), it remains to be confirmed whether GCN5 acetylates $\mathrm{H} 3 \mathrm{~K} 9$ at Hox loci in a manner reminiscent of MOZ.

Csrp2bp

CSRP2BP was first identified in a yeast-2-hybrid screen as a binding partner for the cysteine-rich LIM-only protein CRP2 (Weiskirchen and Gressner 2000). Intriguingly, CSRP2BP (also known as ATAC2) has been purified as part of the GCN5/PCAFcontaining ATAC complex in human HEK293 cells, mouse C2C12 cells (Guelman et al. 2009), and in the Gen5-ATAC complex in Drosophila melanogaster (Suganuma et al. 2008). This suggests that the ATAC complex contains two HATs - CSRP2BP and either GCN5 or PCAF. In Drosophila, there is only one homologue of GCN5 and PCAF 
- Gcn5. Drosophila flies lacking the Csrp2bp homologue atac2 die at the $2^{\text {nd }}$ instar stage, and lack H4K16 acetylation, but not H3K9, H3K14, H4K5, H4K8, or H4K12 acetylation at embryonic stages 12-15 (Suganuma et al. 2008). In contrast, E8.5 mouse embryos lacking Csrp2bp show an approximately 50\% reduction in global H3K9, H4K5, H4K12 and H4K16 acetylation (Guelman et al. 2009). Whether this deficit in histone acetylation is directly due to loss of CSRP2BP HAT activity remains to be determined. Indeed, in Csrp $2 b p^{-/-}$mouse mutants, and in HEK293 cells in which $C S R P 2 B P$ has been depleted via siRNA, there is a significant reduction in GCN5 levels, suggesting that CSRP2BP is required to maintain the GCN5-ATAC complex (Guelman et al. 2009). Hence, a reduction in the HAT activity of GCN5 could explain the decrease in acetylation observed in the absence of CSRP2BP. Whether CSRP2BP actually possesses HAT activity in vivo remains unclear, as a large quantity of purified CSRP2BP only shows weak HAT activity for free histone H4, while purified GCN5 strongly acetylates histone H3 (Guelman et al. 2009). Furthermore, the Gcn5 and Csrp $2 b p$ knockout phenotypes show some overlap. Reminiscent of $G c n 5^{-/}$embryos (Xu et al. 2000b, Yamauchi et al. 2000), $C s r p 2 b p^{-/-}$embryos undergo growth arrest around E9.5, and show extensive apoptosis (Guelman et al. 2009). However, unlike Gcn5 ${ }^{-/}$ embryos, in which the paraxial mesoderm, chordamesoderm, and head mesenchyme do not develop properly (Xu et al. 2000b), mesodermal tissues are correctly specified in Csrp $2 b p^{-/-}$embryos, while extensive apoptosis is observed in the neuroectoderm (Guelman et al. 2009). Given that Gcn5 hypomorphic mice, which live longer than $\mathrm{Gcn}^{-/}$mice, show neural tube closure defects and exencephaly (Lin et al. 2008b), one intriguing possibility is that increased levels of apoptosis in the Csrp $2 b p^{-1-}$ neuroectoderm may also lead to neural tube closure defects later in development. Conditional models of Csrp2bp deletion in the nervous system are required to test this hypothesis. Other models that could explain the phenotype of Csrp2bp mice include the possibility that the GCN5-CSRP2BP-ATAC complex is important for maintaining the neuronal linage, while the other GCN5/PCAF complex, STAGA/TFTC, is responsible for maintaining the mesodermal lineage. The contribution of PCAF to the function of the CSRP2BP-ATAC complex also needs investigation.

\section{Hat1}

Hat1p was first identified in a screen for yeast mutants that were unable to acetylate the histone H4 tail (Kleff et al. 1995). Studies in the yeast Saccharomyces cerevisae 
revealed that Hat1p is unique as it can acetylate free histone $\mathrm{H} 4$, but not $\mathrm{H} 4$ that has been incorporated into nucleosomes (Parthun et al. 1996). It was subsequently shown in human HeLa cells that cytoplasmic HAT1 acetylates free histone H4 at lysine residues 5 and 12 (Chang et al. 1997). Thus, HAT1 is considered important for acetylating newly formed histone $\mathrm{H} 4$, and transporting it to the nucleus for incorporation with newly synthesized DNA (reviewed by Parthun 2007). While a number of biochemical studies on HAT1 have been reported, the importance of HAT1 in vivo has only just begun to be determined. The Hatl knockout mouse has been recently reported (Nagarajan et al. 2013). Consistent with biochemical studies, a reduction in acetylation of H4K5, H4K12, $\mathrm{H} 3 \mathrm{~K} 9, \mathrm{H} 3 \mathrm{~K} 18$ and $\mathrm{H} 3 \mathrm{~K} 27$ is observed on newly synthesized histones in immortalized Hat $^{-/-}$MEFs. Acetylation of these newly formed histones does not appear to be important for proliferation or chromatin formation, as $\mathrm{Hatl}^{-/-}$mice developed until term and die at birth. $\mathrm{Hatl}^{-/-}$pups display defective and underdeveloped lungs due to over proliferation of cells, and die due to inadequate oxygenation of their blood. How a lack of HAT1 leads to the observed increase in proliferation in vivo remains to be understood. The recent construction of a Hat1 knockout mouse provides an important tool for an indepth study of HAT1 during neural development. One indication that HAT1 may play a role in neural development is that Hat 1 mRNA is highly enriched in the neurogenic SVZ-olfactory bulb axis in the adult mouse brain (Lim et al. 2006).

Elp3

The HAT Elp3p was first identified as part of the yeast elongator complex (Wittschieben et al. 1999), and subsequently found to be part the human elongator complex in HeLa cells (Hawkes et al. 2002). The elongator complex consists of six subunits, ELP1-6. The elongator complex interacts with RNA polymerase II and is important for transcriptional elongation through a chromatin substrate (Kim et al. 2002). While a HAT domain at the C-terminal end of ELP3 has been well characterized, an Nterminal radical S-adenosylmethionine (SAM) domain has been predicted to have demethylase activity (Chinenov 2002). While the paternal genome is normally demethylated at $\mathrm{CpG}$ islands after fertilization, knockdown of Elp3 by siRNA in mouse zygotes leads to defective demethylation of the paternal genome (Okada et al. 2010). Whether ELP3 is able to demethylate $\mathrm{CpG}$ islands at later points in development, particularly in primordial germ cells, remains to be determined. Whilst a knockout mouse model of Elp3 has not been published, ELP3 and the elongator complex have 
been identified as playing key roles during neuronal migration, dendritic maturation, and neural disease.

Mutations in the elongator complex component ELPI (also known as IKBKAP) in humans leads to familial dysautonomia, a neuropathy characterized by progressive degeneration of the sensory and autonomic nervous system (Slaugenhaupt et al. 2001). While no inactivating mutations in human ELP3 have been reported, SNPs in ELP3 have been found to correlate with increased risk of amyotrophic later sclerosis (ALS), a motor neuron disease that normally leads to death within three years of diagnosis (Simpson et al. 2009). The authors of this study also found mutations in Elp3 in a Drosophila screen for genes important for neuronal communication. Mutations in Drosophila Elp3 lead to defective depolarization of retina photoreceptors, while morpholino knockdown of elp3 in zebrafish results in abnormal branching of axons and dendrites associated with motor neurons (Simpson et al. 2009). The role of ELP3 and the elongator complex in the mammalian nervous system has also been investigated through siRNA-mediated knockdown studies. Knockdown of either Elpl or Elp3 in E14.5 mouse cortices in utero results in slower migration of neuronal precursors from the proliferative ventricular zone to the cortical plate. Furthermore, in these mice at postnatal day 2 and 17, the dendrites emanating from mature projection neurons in the motor and somatosensory regions of the cerebral cortex are smaller and less branched (Creppe et al. 2009). Strikingly, this defect in dendrite branching correlates with reduced acetylation of $\alpha$-tubulin in the cytoplasm of Elp3 knockdown cells, suggesting that ELP3 acetylates $\alpha$-tubulin in vivo. Consistently, elongator complex members ELP1, ELP3, ELP4, and ELP5 are mostly cytoplasmic and not nuclear. Furthermore, overexpressed ELP3 coimmunoprecipitates with $\alpha$-tubulin in HEK293 cells, and overexpression of a dominant negative form of $\alpha$-tubulin (K40A), which cannot be acetylated, leads to the same phenotype as Elp3 knockdown (Creppe et al. 2009). Thus, it appears that a decrease in Elp3 leads to delayed development of the cerebral cortex, and ELP3 is important for maturation of neurons. While ELP3 in the elongator complex can acetylate free histone H3 in cell-free assays (Hawkes et al. 2002), and given that ELP3 is apparently important for transcriptional elongation by RNA polymerase II (Kim et al. 2002), the role of ELP3 in regulating transcription in intact cells still needs to be determined. Given that proliferation and apoptosis in the developing cerebral cortex in mice are unaffected despite a knockdown of Elp3 (Creppe et al. 2009), it is 
unlikely that ELP3 is essential for transcriptional elongation. Furthermore, there are conflicting reports regarding whether the elongator complex can sufficiently acetylate histones incorporated into nucleosomes. Purified yeast Elp3p-elongator complex has been shown to acetylate nucleosomal histones H3 and H4 (Winkler et al. 2002), while purified human elongator complex is apparently deficient in acetylating nucleosomal, but not free histones (Kim et al. 2002). These differences are likely related to the presence or absence of different subunits of the elongator complex in the different studies. Nevertheless, whether the biochemical data from cell-free assays linking ELP3 to transcriptional elongation can be recapitulated in vivo in mammals remains to be seen.

While the biochemistry of the GNAT family members, including their complexes, has been very well studied, the biological roles of all five members in vivo are only now starting to be determined. Future studies are required to correlate the current biochemical data with biological systems to further understand this structurally and functionally diverse family.

\section{NCOA family}

The Nuclear receptor co-activator (NCOA) family of HATs consists of four members (Figure 1). Three of the four members, NCOA1 (SRC1, KAT13A), NCOA2 (TIF2, KAT13C, p160), and NCOA3 (SCR3, KAT13B, TRAM1, ACTR), have identical domain structure and a high level of sequence homology. Furthermore, biochemical studies have shown that NCOA1, NCOA2, and NCOA3 can interact with a similar set of nuclear receptors, and have overlapping functions in some biological roles (see below). Hence, these three members of the family will be discussed together. The fourth member of the NCOA family, Circadian locomotor output cycles kaput (CLOCK, KAT13D), shares a similar domain structure with its family members (Figure 1). However, the HAT domain of CLOCK is more similar to the MYST-family, and shares a moderate level of sequence homology with the MYST-HAT domain (Doi et al. 2006).

\section{Ncoal, Ncoa2 and Ncoa3}

Purified and over-expressed NCOA1, NCOA2 and NCOA3, have all been shown to interact with a number of nuclear receptors, and stimulate their transcription-activating functions in vitro as assayed by various reporter constructs. In particular, NCOA1 
interacts with and stimulates the transcription-activating activity of retinoid $\mathrm{X}$ receptor (RXR), progesterone receptor (PR), estrogen receptor (ER), glucocorticoid receptor (GR), and thyroid hormone receptor (THR) (Spencer et al. 1997), NCOA2 of vitamin D receptor, RXR, retinoid A receptor (RAR), GR, ER and androgen receptor (Hong et al. 1997, Walfish et al. 1997), and NCOA3 of RAR, THR, and vitamin-D receptor (Chen et al. 1997). In addition, all three NCOA proteins have been shown to interact with other HATs, namely p300, CBP, and PCAF in biochemical studies (Chen et al. 1997, Spencer et al. 1997, Torchia et al. 1997, Voegel et al. 1998, Yao et al. 1996). Thus, the three NCOA proteins are thought to form a bridge, whereby they interact with DNA-bound nuclear receptors, and recruit other HATs that can modify the local chromatin environment in a ligand-dependent manner. Interestingly, purified NCOA1 (Spencer et al. 1997) and NCOA3 (Chen et al. 1997) have been shown to have HAT activity when incubated with free histones and mononucleosomes. Whether these proteins along with NCOA2 possess endogenous HAT activity in vivo, or whether the chromatin modifying ability of NCOA-proteins depends on their recruitment of p300, CBP and PCAF, is controversial and requires further verification. Deficiencies in histone acetylation have not been investigated in knockout mouse models of Ncoal, Ncoa2 or Ncoa3. However, through knockout studies, a number of unique and overlapping roles have been described for NCOA1, NCOA2 and NCOA3 across diverse functions such as cancer, regulation of metabolism, response to hormones, and fertility (reviewed by Louet and O'Malley 2007, Xu and Li 2003, Xu et al. 2009). While the knockout phenotypes of Ncoal (Xu et al. 1998), Ncoa2 (Gehin et al. 2002), and Ncoa3 (Xu et al. 2000a), are relatively mild compared to those of other HATs, they do implicit a function for this family in sexual development, and to a lesser extent, in neural development.

NCOA1 expression levels are low in neural progenitors and stem cells cultured in vitro as neurospheres. However, NCOA1 expression is strongly up-regulated in cells that are committed towards the neuronal lineage (Nishihara et al. 2007). While no defects in cerebral cortex development have been described in Ncoal-knockout mice, a developmental delay in the formation of the Purkinjie cell layer in the cerebellum has been reported. The production of Purkinjie cell progenitors in $\mathrm{Ncoal}^{-/-}$embryos is delayed by approximately two days, and at birth, no Purkinjie cell layer is evident in Ncoal $^{-/-}$pups compared to a well-established layer in wild type pups (Nishihara et al. 2003). Interestingly, no defects in the Purkinjie cells are evident in $\mathrm{Ncoal}^{-/-}$pups at 
postnatal day 10, which can be attributed to the compensatory up-regulation of Ncoa2 expression in $\mathrm{Ncoal}^{-/}$Purkinjie cells to above wild type levels (Nishihara et al. 2007). Nevertheless, adult $\mathrm{Ncoal}^{-/}$mice present with moderate motor impairments, suggesting that delayed Purkinjie cell development has long-term consequences.

The adult brain is highly responsive to hormones, which are an important mechanism for sexual maturation during development, as well as sexual behavior in adult mice. One structure important for sexual development and behavior is the sexually dimorphic nucleus (SDN), which is found in the hypothalamus, and is 2.5 -fold larger in males than females (Swaab and Fliers 1985, Tsukahara 2009). Upon knockdown of Ncoal in the hypothalamus, female rats were less responsive to neonatal testosterone treatment and showed reduced de-feminization compared to females with normal Ncoal levels (Auger et al. 2000). While this finding begs further investigation, it nevertheless indicates a function for NCOA1 in regulating hormone responses during sexual maturation in the postnatal brain.

While no other defects in the nervous system of Ncoal, Ncoa2 and Ncoa3 mutant mice have been described, Ncoal and Ncoa 2 expression is detectable in the olfactory bulb, piriform cortex, hippocampus, amygdala and the hypothalamus (Nishihara et al. 2003). Furthermore, Ncoal is strongly expressed in the neural tube at E11.5, and in the telencephalon at E14.5 (Misiti et al. 1999). While Nishihara et al. (2003) only reported $N c o a 3$ expression in the hippocampus, using a $\beta$-galactosidase reporter construct, $\mathrm{Xu}$ and co-workers detected Ncoa3 expression in hippocampal neurons, olfactory bulb neurons, and in the internal granular layer, but not Purkinjie cells of the cerebellum $(\mathrm{Xu}$ et al. 2000a). These expression patterns suggest that Ncoal, Ncoa2 and Ncoa3 may still have unrecognized roles in nervous system, which may be overlapping between these three similar proteins.

While only a limited role for NCOA1 has been established during neural development, given the importance of hormone production and the high responsiveness of the brain to hormones during the development and maturation of the nervous system, further roles for NCOA1, NCOA2 and NCOA3 are likely to exist. Given the importance of p300 and CBP during nervous system development (discussed above), and the fact that NCOA1, 
NCOA2 and NCOA3 require these HATs for their transcription-activating functions, it is exciting to speculate that at least part of the phenotype of $p 300$ and $C b p$ knockout mice may be due to the inability of NCOA proteins to stimulate transcription of their target genes. Furthermore, a subset of abnormalities observed in RTS patients including stunted growth may be linked to hormones such as the growth hormone pathway, which are mediated by NCOAs. While technically difficult, it would be exciting to examine compound Ncoa mutant mice, especially ones with conditional tissue-specific knockouts. Furthermore, it would be enlightening to determine how dependent NCOA1, NCOA2 and NCOA3 are on the HAT activity of p300 and CBP in vivo.

\section{Clock}

CLOCK was first identified in an ENU (N-ethyl-N-nitrosourea) screen for genes regulating circadian rhythms (Vitaterna et al. 1994). Circadian rhythms drive the physiology and behavior of animals over a 24-hour cycle. The central regulation of circadian rhythms is mediated in the suprachiasmatic nucleus (SCN) of the hypothalamus (Reppert and Weaver 2002). The transcription-activating properties of CLOCK and its dimerization partner BMAL1 (Gekakis et al. 1998), are thought to be central in the process of transcriptionally activating circadian genes in the SCN in a cyclic manner (Bunger et al. 2000, Vitaterna et al. 1994). However, a report by DeBruyne and co-workers on the knockout Clock allele, which has a much milder phenotype than the ENU Clock mutant in dysregulation of circadian rhythms, has questioned the central role of CLOCK in circadian rhythms (Debruyne et al. 2006). Indeed, in Clock $^{-/-}$mice, expression of the proposed target genes of CLOCK, mPerl, Rev-erb $\alpha$ and $A v p$, cycle relatively normally over a 24-hour period. However, the peak mRNA expression levels of these target genes are not reached. Consistently, purified CLOCK has been shown to acetylate histones $\mathrm{H} 3$ and $\mathrm{H} 4$ presented as free histones or mononucleosomes, an activity that is stimulated by its binding partner BMAL1 (Doi et al. 2006). Histone H3 acetylation fluctuates in a circadian cyclic manner at CLOCK target loci mPerl and mPer2 (Etchegaray et al. 2003), and the absence of CLOCK may lead to decreased acetylation and HAT activity at its target loci. However, whether CLOCK has intrinsic HAT activity in vivo, or simply recruits other HATs to modify chromatin associated with transcriptional activation, remains to be determined. Indeed, in liver extracts, endogenous p300 coimmunoprecipitates with CLOCK (Etchegaray et 
al. 2003). Importantly, no developmental defects have been reported in Clock knockout mice, which are viable and fertile, suggesting that CLOCK is likely to play a minor role during embryonic development.

\section{Transcription-related HATs}

In eukaryotes, transcription from a chromatin template requires the establishment of the pre-initiation complex and RNA polymerase at gene promoters (Hochheimer and Tjian 2003, Lemon and Tjian 2000, Sims et al. 2004). The general transcription factor containing TFIID and TFIIIC complexes contain components that recognize DNAspecific sequences, and mediate RNA polymerase II and RNA polymerase III transcription, respectively. The TFIID complex consists of TATA-box binding protein (TBP) and 13 TBP-associated factors (TAFs). Furthermøre, TFIID can recognize and bind to DNA promoter sequences, and mediates the recruitment and stabilization of TFII complexes and RNA polymerase II at promoters (reviewed by Lemon and Tjian 2000, Papai et al. 2011). In contrast, TFIIIC can directly bind to the A and B boxes in promoters of RNA polymerase III genes such as tRNAs (Lunyak and Atallah 2011). Interestingly, the largest component of the TFIID complex, TAF1 (KAT4, TF 250 , Mizzen et al. 1996), and three components of the TFIIIC complex, GTF3C1, (TFIIIC $\alpha$, TFIIIC220), GTF3C2 (TFIIIC $\beta$, TFIIIC110), and GTF3C4 (TFIIIC $\delta$, TFIIIC90, KAT12) (Hsieh et al. 1999, Kundu et al. 1999), have been shown to possess HAT activity in extra-cellular HAT assays. This HAT activity is thought to be important for acetylating and mediating chromatin relaxation around target gene loci, thus allowing transcription to progress (Kundu et al. 1999, Wassarman and Sauer 2001). Intriguingly, in addition to the central role for these complexes in transcription, roles for TFIID and TFIIIC in neural development and disease have been suggested.

\section{Taf1}

TAF1 is the largest component of the TFIID complex, and contains two protein kinase domains, E1/E2 ubiquitin ligase activity, and a HAT domain (Figure 1) (Wassarman and Sauer 2001). Purified human, Drosophila, and yeast Taf1p all possess HAT activity, with the activity of Drosophila Taf1 directed towards histones H3 and H4 (Mizzen et al. 1996). Interestingly, a brain-specific isoform of TAF1 has been described, which was first found to be lacking in patients suffering from X-Linked 
Dystonia-Parkinsonism (XDP) (Makino et al. 2007). XDP is a recessively inherited neurodegenerative disorder, prevalent in approximately 5.24 per 100,000 people on Panay Island in the Philippines (Lee et al. 2002). XDP patients present with dystonia and Parkinson's like symptoms including tremors, twisting of distal limbs, slow movement, and postural instability. Being an X-linked disorder, it is much more common in men than women. Makino and co-workers (2007) found that inheritance for XDP was related to a transposon inserted into intron 32 of the TAF1 gene. This insertion lead to the specific silencing of a neuronal specific isoform of TAF1 $(\mathrm{N}$ $T A F 1$ ), which consists of an extra 6 bp from exon 34 in the mRNA, and the insertion of two extra amino acids, an alanine and a lysine into the TAF1 protein. Indeed, both the $\mathrm{N}-\mathrm{TAF} 1$ protein and $\mathrm{N}$-Taf1 mRNA in mice and rats are only detected in the brain, and not other tissues, while the major isoform of TAF1 is ubiquitously expressed consistent with its role in RNA polymerase II mediated transcription (Jambaldorj et al. 2012, Sako et al. 2011). The expression of N-TAF1 is widespread in the brain, being evident in the cerebral cortex, striatum, substantia nigra, thalamus, hippocampus and cerebellum (Sako et al. 2011). In the striatum, the region showing degeneration in XDP, endogenous N-TAF1 protein is largely confined to the nucleus of medium spiny neurons, and is absent from cholinergic neurons. Interestingly, medium spiny neurons are the most vulnerable in XDP, while cholinergic neurons are largely spared (Goto et al. 2005), suggesting that N-TAF1 may provide protection against cell death or other cellular insults. Given the importance of N-TAF1 in XDP physiology, it is likely that NTAF1 may have a role during neural development. While this will be difficult to study in human XDP patients, mouse models specifically removing the $\mathrm{N}$-Tafl isoform will be highly informative. Furthermore, importance of the HAT activity of N-TAF1 in XDP remains to be determined.

\section{TFIIIC complex}

While the TFIIIC complex has classically been associated with RNA polymerase III based transcription, additional roles for the TFIIIC complex that do not involve RNA polymerase III transcription have recently been identified (reviewed by Kirkland et al. 2013). Indeed, over $85 \%$ of genomic sites with TFIIIC binding do not overlap with RNA polymerase III binding in mouse ESCs (Carriere et al. 2012), suggesting additional roles for TFIIIC. A recent study by Crepaldi and co-workers (2013) found that the TFIIIC complex binds to short interspersed elements (SINEs) in neurons, and 
inhibits premature mRNA expression of genes that are normally activated following activity-based stimulus. SINEs are repetitive DNA sequences generated by retrotransposable elements, and contain DNA sequences (A-box and B-box) that are recognized by TFIIIC (reviewed by Lunyak and Atallah 2011). Crepaldi et al. (2013) induced neuronal activity by providing mice with a novel and enriched environment for 45 minutes or three hours prior to analysis. In response to the enriched environment, an increase in $\mathrm{H} 3 \mathrm{~K} 9 / 14 \mathrm{ac}$, and recruitment of the TFIIIC component GTF3C1 to SINEs upstream of immediate early response genes including $c$-Fos and Gadd45b is observed (Crepaldi et al. 2013). However, in the absence of neuronal stimulation, a similar effect is observed when the TFIIIC component Gtf3c5 is knocked down by siRNA. In response to Gtf3c5 knockdown, increased levels of H3K9/14ac at SINEs associated with $c$-Fos and Gadd45b are observed, concomitant with an increase in transcription from these gene loci. Consistently, when cortical neurons are stimulated in vitro with potassium chloride, the $c-F o s$ and Gadd45b gene loci are recruited to transcriptional factories that contain active RNA polymerase II. However, if $G t f 3 c 5$ is knocked down, $c$-Fos and Gadd45b are recruited to transcription factories even in the absence of neuronal stimulation. This function of TFIIIC has biological consequences in the neural system. Both stimulation of cortical neurons, or Gtf3c5 knockdown without neuronal stimulation, lead to an increase in the number and branching of dendrites (Crepaldi et al. 2013). Thus, it appears that in neurons, the TFIIIC complex is important for binding to SINEs and repressing the premature activation of genes that are poised for activation. Given that a large number of poised genes are activated or repressed during embryonic development (Bernstein et al. 2006, Mikkelsen et al. 2007), and that TFIIIC has 2652 binding sites in mouse ESCs (Carriere et al. 2012), it would be of interest to determine how TFIIIC binding to SINEs and other DNA elements is able to regulate the 3D chromatin structure, and thereby modulate the transcriptional activity of a large number of genes. The fact that three components of the TFIIIC complex have HAT activity (Kundu et al. 1999), while H3K9/14ac is increased at SINEs when TFIIIC is removed from DNA by knockdown of Gtf3c5 (Crepaldi et al. 2013), is counterintuitive. Whether the HAT activity of TFIIIC is required at SINEs and other genomic elements remains to be determined. It is plausible that TFIIIC acts via a different mechanism at SINEs, where it may inhibit binding of molecular complexes that recruit the associated genes to nuclear transcriptional factories, while at RNA polymerase III associated sites, TFIIIC is required to acetylate and relax the associated chromatin. 


\section{Concluding Remarks}

The nineteen HATs identified so far (Figure 1) play a diverse set of roles in biology. Research over the past decade has identified specialized roles for these HATs during neural development (Figure 2). These roles include regulating the proliferation of neural progenitors during embryonic development and in the adult brain, ensuring correct patterning of the brain and migration of progenitors during embryogenesis, activating transcription from appropriate gene loci during differentiation, and mediating proper cell maturation, survival and processes in neural cells which underpin the functionality of the human brain. Not surprisingly, mutations in HATs have been identified in a number of developmental disorders leading to intellectual disability and neurodegeneration (Table 1). Continued efforts are required to link the large set of biochemical data available on HATs to their in vivo function. Furthermore, as proper neural development requires the proper coordination of HAT expression in a space and time dependent manner, it is important to ascertain how the expression and catalytic activities of HATs are regulated. Downstream of HAT activation, how HATs regulate the $3 \mathrm{D}$ structure of chromatin and act in concert with a number of other chromatin regulators to mediate the timely activation of gene expression remains incompletely understood. Further characterization of HAT function at the molecular and organism level will provide us with a greater appreciation of their role during neural development, and may indeed provide opportunities for the treatment of intellectual disorders and neurodegeneration.

\section{Acknowledgements}

I would like to thank Tim Thomas, Hannah Vanyai and Farrah El-Saafin for stimulating discussions and comments on the manuscript. My apologies to colleagues whose important research could not be discussed here due to space limitations. This work was supported by the Australian National Health and Medical Research Council (scholarship to B.N.S.), operational infrastructure grants from the Australian Federal Government (IRISS), and the Victorian State Government (OIS). 


\section{References}

Akhtar A, Becker PB (2000) Activation of transcription through histone H4 acetylation by MOF, an acetyltransferase essential for dosage compensation in Drosophila. Molecular cell 5:367-375

Alarcon JM, Malleret G, Touzani K, Vronskaya S, Ishii S, Kandel ER, Barco A (2004) Chromatin acetylation, memory, and LTP are impaired in CBP+/- mice: a model for the cognitive deficit in Rubinstein-Taybi syndrome and its amelioration. Neuron 42:947-959

Alexander T, Nolte C, Krumlauf R (2009) Hox genes and segmentation of the hindbrain and axial skeleton. Annu Rev Cell Dev Biol 25:431-456

Allis CD, Berger SL, Cote J, Dent S, Jenuwien T, Kouzarides T, Pillus L, Reinberg D, Shi Y, Shiekhattar R, Shilatifard A, Workman J, Zhang Y (2007) New nomenclature for chromatin-modifying enzymes. Cell 131:633-636

Auger AP, Tetel MJ, McCarthy MM (2000) Steroid receptor coactivator-1 (SRC-1) mediates the development of sex-specific brain morphology and behavior. Proc Natl Acad Sci U S A 97:7551-7555

Azevedo FA, Carvalho LR, Grinberg LT, Farfel JM, Ferretti RE, Leite RE, Jacob Filho W, Lent R, Herculano-Houzel S (2009) Equal numbers of neuronal and nonneuronal cells make the human brain an isometrically scaled-up primate brain. J Comp Neurol 513:532-541

Bannister AJ, Kouzarides T (2011) Regulation of chromatin by histone modifications. Cell Res 21:381-395

Berger SL (2007) The complex language of chromatin regulation during transcription. Nature 447:407-412

Bernstein BE, Mikkelsen TS, Xie X, Kamal M, Huebert DJ, Cuff J, Fry B, Meissner A, Wernig M, Plath K, Jaenisch R, Wagschal A, Feil R, Schreiber SL, Lander ES (2006) A bivalent chromatin structure marks key developmental genes in embryonic stem cells. Cell 125:315-326

Bhattacharya S, Eckner R, Grossman S, Oldread E, Arany Z, D'Andrea A, Livingston DM (1996) Cooperation of Stat2 and p300/CBP in signalling induced by interferon-alpha. Nature 383:344-347

Bhattacherjee V, Horn KH, Singh S, Webb CL, Pisano MM, Greene RM (2009) $\mathrm{CBP} / \mathrm{p} 300$ and associated transcriptional co-activators exhibit distinct expression 
patterns during murine craniofacial and neural tube development. The International journal of developmental biology 53:1097-1104

Borrow J, Stanton VP, Jr., Andresen JM, Becher R, Behm FG, Chaganti RS, Civin CI, Disteche C, Dube I, Frischauf AM, Horsman D, Mitelman F, Volinia S, Watmore AE, Housman DE (1996) The translocation $\mathrm{t}(8 ; 16)(\mathrm{p} 11 ; \mathrm{p} 13)$ of acute myeloid leukaemia fuses a putative acetyltransferase to the CREB-binding protein. Nature genetics 14:33-41

Brownell JE, Zhou J, Ranalli T, Kobayashi R, Edmondson DG, Roth SY, Allis CD (1996) Tetrahymena histone acetyltransferase A: a homolog to yeast Gcn5p linking histone acetylation to gene activation. Cell 84:843-851

Bu P, Evrard YA, Lozano G, Dent SY (2007) Loss of Gen5 acetyltransferase activity leads to neural tube closure defects and exencephaly in mouse embryos. Molecular and cellular biology 27:3405-3416

Bunger MK, Wilsbacher LD, Moran SM, Clendenin C, Radcliffe LA, Hogenesch JB, Simon MC, Takahashi JS, Bradfield CA (2000) Mop3 is an essential component of the master circadian pacemaker in mammals. Cell 103:1009-1017

Callebaut I, Mornon JP (2012) The PWAPA cassette: Intimate association of a PHDlike finger and a winged-helix domain in proteins included in histone-modifying complexes. Biochimie 94:2006-2012

Campeau PM, Kim JC, Lu JT, Schwartzentruber JA, Abdul-Rahman OA, Schlaubitz S, Murdock DM, Jiang MM, Lammer EJ, Enns GM, Rhead WJ, Rowland J, Robertson SP, Cormier-Daire V, Bainbridge MN, Yang XJ, Gingras MC, Gibbs RA, Rosenblatt DS, Majewski J, Lee BH (2012) Mutations in KAT6B, encoding a histone acetyltransferase, cause Genitopatellar syndrome. American journal of human genetics 90:282-289

Cao X, Sudhof TC (2001) A transcriptionally [correction of transcriptively] active complex of APP with Fe65 and histone acetyltransferase Tip60. Science 293:115120

Carriere L, Graziani S, Alibert O, Ghavi-Helm Y, Boussouar F, Humbertclaude H, Jounier S, Aude JC, Keime C, Murvai J, Foglio M, Gut M, Gut I, Lathrop M, Soutourina J, Gerard M, Werner M (2012) Genomic binding of Pol III transcription machinery and relationship with TFIIS transcription factor distribution in mouse embryonic stem cells. Nucleic Acids Res 40:270-283 
Champagne N, Bertos NR, Pelletier N, Wang AH, Vezmar M, Yang Y, Heng HH, Yang XJ (1999) Identification of a human histone acetyltransferase related to monocytic leukemia zinc finger protein. J Biol Chem 274:28528-28536

Chan HM, La Thangue NB (2001) p300/CBP proteins: HATs for transcriptional bridges and scaffolds. Journal of cell science 114:2363-2373

Chang L, Loranger SS, Mizzen C, Ernst SG, Allis CD, Annunziato AT (1997) Histones in transit: cytosolic histone complexes and diacetylation of $\mathrm{H} 4$ during nucleosome assembly in human cells. Biochemistry 36:469-480

Chen H, Lin RJ, Schiltz RL, Chakravarti D, Nash A, Nagy L, Privalsky ML, Nakatani Y, Evans RM (1997) Nuclear receptor coactivator ACTR is a novel histone acetyltransferase and forms a multimeric activation complex with P/CAF and CBP/p300. Cell 90:569-580

Chinenov Y (2002) A second catalytic domain in the Elp3 histone acetyltransferases: a candidate for histone demethylase activity? Trends Biochem Sci 27:115-117

Chokroverty S (2009) Sleep and neurodegenerative diseases. Seminars in neurology 29:446-467

Choudhary C, Kumar C, Gnad F, Nielsen ML, Rehman M, Walther TC, Olsen JV, Mann M (2009) Lysine acetylation targets protein complexes and co-regulates major cellular functions. Science 325:834-840

Chrivia JC, Kwok RP, Lamb N, Hagiwara M, Montminy MR, Goodman RH (1993) Phosphorylated CREB binds specifically to the nuclear protein CBP. Nature 365:855-859

Clayton-Smith J, O'Sullivan J, Daly S, Bhaskar S, Day R, Anderson B, Voss AK, Thomas T, Biesecker LG, Smith P, Fryer A, Chandler KE, Kerr B, Tassabehji M, Lynch SA, Krajewska-Walasek M, McKee S, Smith J, Sweeney E, Mansour S, Mohammed S, Donnai D, Black G (2011) Whole-exome-sequencing identifies mutations in histone acetyltransferase gene KAT6B in individuals with the SayBarber-Biesecker variant of Ohdo syndrome. American journal of human genetics 89:675-681

Crepaldi L, Policarpi C, Coatti A, Sherlock WT, Jongbloets BC, Down TA, Riccio A (2013) Binding of TFIIIC to sine elements controls the relocation of activitydependent neuronal genes to transcription factories. PLoS genetics 9:e1003699

Creppe C, Malinouskaya L, Volvert ML, Gillard M, Close P, Malaise O, Laguesse S, Cornez I, Rahmouni S, Ormenese S, Belachew S, Malgrange B, Chapelle JP, 
Siebenlist U, Moonen G, Chariot A, Nguyen L (2009) Elongator controls the migration and differentiation of cortical neurons through acetylation of alphatubulin. Cell 136:551-564

Davey CA, Sargent DF, Luger K, Maeder AW, Richmond TJ (2002) Solvent mediated interactions in the structure of the nucleosome core particle at 1.9 a resolution. $\mathrm{J}$ Mol Biol 319:1097-1113

de Ruijter AJ, van Gennip AH, Caron HN, Kemp S, van Kuilenburg AB (2003) Histone deacetylases (HDACs): characterization of the classical HDAC family. Biochem $\mathbf{J}$ 370:737-749

Debruyne JP, Noton E, Lambert CM, Maywood ES, Weaver DR, Reppert SM (2006) A clock shock: mouse CLOCK is not required for circadian oscillator function. Neuron 50:465-477

Doi M, Hirayama J, Sassone-Corsi P (2006) Circadian regulator CLOCK is a histone acetyltransferase. Cell 125:497-508

Doyon Y, Cayrou C, Ullah M, Landry AJ, Cote V, Selleck W, Lane WS, Tan S, Yang XJ, Cote J (2006) ING tumor suppressor proteins are critical regulators of chromatin acetylation required for genome expression and perpetuation. Molecular cell 21:51-64

Doyon Y, Selleck W, Lane WS, Tan S, Cote J (2004) Structural and functional conservation of the NuA4 histone acetyltransferase complex from yeast to humans. Molecular and cellular biology 24:1884-1896

Dutnall RN, Tafrov ST, Sternglanz R, Ramakrishnan V (1998) Structure of the histone acetyltransferase Hat1: a paradigm for the GCN5-related N-acetyltransferase superfamily. Cell 94:427-438

Eckner R, Ewen ME, Newsome D, Gerdes M, DeCaprio JA, Lawrence JB, Livingston DM (1994) Molecular cloning and functional analysis of the adenovirus E1Aassociated $300-\mathrm{kD}$ protein $(\mathrm{p} 300)$ reveals a protein with properties of a transcriptional adaptor. Genes Dev 8:869-884

Etchegaray JP, Lee C, Wade PA, Reppert SM (2003) Rhythmic histone acetylation underlies transcription in the mammalian circadian clock. Nature 421:177-182

Feil R, Fraga MF (2011) Epigenetics and the environment: emerging patterns and implications. Nature reviews Genetics 13:97-109 
Forlani S, Lawson KA, Deschamps J (2003) Acquisition of Hox codes during gastrulation and axial elongation in the mouse embryo. Development 130:38073819

Garcia-Ramirez M, Rocchini C, Ausio J (1995) Modulation of chromatin folding by histone acetylation. J Biol Chem 270:17923-17928

Gehin M, Mark M, Dennefeld C, Dierich A, Gronemeyer H, Chambon P (2002) The function of TIF2/GRIP1 in mouse reproduction is distinct from those of SRC-1 and p/CIP. Molecular and cellular biology 22:5923-5937

Gekakis N, Staknis D, Nguyen HB, Davis FC, Wilsbacher LD, King DP, Takahashi JS, Weitz CJ (1998) Role of the CLOCK protein in the mammalian circadian mechanism. Science 280:1564-1569

Georgala PA, Carr CB, Price DJ (2011) The role of Pax6 in forebrain development. Developmental neurobiology 71:690-709

Gilbert SF (2003) Developmental Biology. Sinauer Associates Inc., Sunderland, MA, USA

Goodman RH, Smolik S (2000) CBP/p300 in cell growth, transformation, and development. Genes Dev 14:1553-1577

Goto S, Lee LV, Munoz EL, Tooyama I, Tamiya G, Makino S, Ando S, Dantes MB, Yamada K, Matsumoto S, Shimazu H, Kuratsu J, Hirano A, Kaji R (2005) Functional anatomy of the basal ganglia in $\mathrm{X}$-linked recessive dystoniaparkinsonism. Annals of neurology 58:7-17

Gotz M, Huttner WB (2005) The cell biology of neurogenesis. Nature reviews Molecular cell biology 6:777-788

Greene ND, Copp AJ (2009) Development of the vertebrate central nervous system: formation of the neural tube. Prenatal diagnosis 29:303-311

Guelman S, Kozuka K, Mao Y, Pham V, Solloway MJ, Wang J, Wu J, Lill JR, Zha J (2009) The double-histone-acetyltransferase complex ATAC is essential for mammalian development. Molecular and cellular biology 29:1176-1188

Gupta A, Guerin-Peyrou TG, Sharma GG, Park C, Agarwal M, Ganju RK, Pandita S, Choi K, Sukumar S, Pandita RK, Ludwig T, Pandita TK (2008) The mammalian ortholog of Drosophila MOF that acetylates histone H4 lysine 16 is essential for embryogenesis and oncogenesis. Molecular and cellular biology 28:397-409 
Haberland M, Montgomery RL, Olson EN (2009) The many roles of histone deacetylases in development and physiology: implications for disease and therapy. Nature reviews Genetics 10:32-42

Hawkes NA, Otero G, Winkler GS, Marshall N, Dahmus ME, Krappmann D, Scheidereit C, Thomas CL, Schiavo G, Erdjument-Bromage H, Tempst P, Svejstrup JQ (2002) Purification and characterization of the human elongator complex. J Biol Chem 277:3047-3052

Hayakawa T, Nakayama J (2011) Physiological roles of class I HDAC complex and histone demethylase. Journal of biomedicine \& biotechnology 2011:129383

Heintzman ND, Stuart RK, Hon G, Fu Y, Ching CW, Hawkins RD, Barrera LO, Van Calcar S, Qu C, Ching KA, Wang W, Weng Z, Green RD, Crawford GE, Ren B (2007) Distinct and predictive chromatin signatures of transcriptional promoters and enhancers in the human genome. Nature genetics 39:311-318

Henry RA, Kuo YM, Andrews AJ (2013) Differences in Specificity and Selectivity Between CBP and p300 Acetylation of Histone H3 and H3/H4. Biochemistry 52:5746-5759

Hilfiker A, Hilfiker-Kleiner D, Pannuti A, Lucchesi JC (1997) mof, a putative acetyl transferase gene related to the Tip60 and MOZ human genes and to the SAS genes of yeast, is required for dosage compensation in Drosophila. EMBO J $16: 2054-2060$

Hochheimer A, Tjian R (2003) Diversified transcription initiation complexes expand promoter selectivity and tissue-specific gene expression. Genes Dev 17:13091320

Hong H, Kohli K, Garabedian MJ, Stallcup MR (1997) GRIP1, a transcriptional coactivator for the AF-2 transactivation domain of steroid, thyroid, retinoid, and vitamin D receptors. Molecular and cellular biology 17:2735-2744

Hong L, Schroth GP, Matthews HR, Yau P, Bradbury EM (1993) Studies of the DNA binding properties of histone $\mathrm{H} 4$ amino terminus. Thermal denaturation studies reveal that acetylation markedly reduces the binding constant of the $\mathrm{H} 4$ "tail" to DNA. J Biol Chem 268:305-314

Hsieh YJ, Kundu TK, Wang Z, Kovelman R, Roeder RG (1999) The TFIIIC90 subunit of TFIIIC interacts with multiple components of the RNA polymerase III machinery and contains a histone-specific acetyltransferase activity. Molecular and cellular biology 19:7697-7704 
Hu Y, Fisher JB, Koprowski S, McAllister D, Kim MS, Lough J (2009) Homozygous disruption of the Tip60 gene causes early embryonic lethality. Dev Dyn 238:2912-2921

Imayoshi I, Sakamoto M, Ohtsuka T, Takao K, Miyakawa T, Yamaguchi M, Mori K, Ikeda T, Itohara S, Kageyama R (2008) Roles of continuous neurogenesis in the structural and functional integrity of the adult forebrain. Nat Neurosci 11:11531161

Jaenisch R, Bird A (2003) Epigenetic regulation of gene expression: how the genome integrates intrinsic and environmental signals. Nature genetics 33 Suppl:245-254

Jambaldorj J, Makino S, Munkhbat B, Tamiya G (2012) Sustained expression of a neuron-specific isoform of the Taf 1 gene in development stages and aging in mice. Biochemical and biophysical research communications 425:273-277

Jin Q, Yu LR, Wang L, Zhang Z, Kasper LH, Lee JE, Wang C, Brindle PK, Dent SY, Ge K (2011) Distinct roles of GCN5/PCAF-mediated H3K9ac and CBP/p300mediated H3K18/27ac in nuclear receptor transactivation. EMBO J 30:249-262

Johnson AA, Sarthi J, Pirooznia SK, Reube W, Elefant F (2013) Increasing Tip60 HAT levels rescues axonal transport defects and associated behavioral phenotypes in a Drosophila Alzheimer's disease model. J Neurosci 33:7535-7547

Josselyn SA (2005) What's right with my mouse model? New insights into the molecular and cellular basis of cognition from mouse models of Rubinstein-Taybi Syndrome. Learning \& memory 12:80-83

Kalkhoven E (2004) CBP and p300: HATs for different occasions. Biochemical pharmacology 68:1145-1155

Kamine J, Elangovan B, Subramanian T, Coleman D, Chinnadurai G (1996) Identification of a cellular protein that specifically interacts with the essential cysteine region of the HIV-1 Tat transactivator. Virology 216:357-366

Kasper LH, Boussouar F, Ney PA, Jackson CW, Rehg J, van Deursen JM, Brindle PK (2002) A transcription-factor-binding surface of coactivator p300 is required for haematopoiesis. Nature 419:738-743

Katsumoto T, Aikawa Y, Iwama A, Ueda S, Ichikawa H, Ochiya T, Kitabayashi I (2006) MOZ is essential for maintenance of hematopoietic stem cells. Genes Dev 20:1321-1330

Kim CH, Kim JW, Jang SM, An JH, Song KH, Choi KH (2012) Transcriptional activity of paired homeobox Pax6 is enhanced by histone acetyltransferase Tip60 during 
mouse retina development. Biochemical and biophysical research communications $424: 427-432$

Kim JH, Lane WS, Reinberg D (2002) Human Elongator facilitates RNA polymerase II transcription through chromatin. Proc Natl Acad Sci U S A 99:1241-1246

Kinoshita A, Whelan CM, Berezovska O, Hyman BT (2002) The gamma secretasegenerated carboxyl-terminal domain of the amyloid precursor protein induces apoptosis via Tip60 in H4 cells. J Biol Chem 277:28530-28536

Kirkland JG, Raab JR, Kamakaka RT (2013) TFIIIC bound DNA elements in nuclear organization and insulation. Biochim Biophys Acta 1829:418-424

Kleff S, Andrulis ED, Anderson CW, Sternglanz R (1995) Identification of a gene encoding a yeast histone H4 acetyltransferase. J Biol Chem 270:24674-24677

Kornberg RD (1974) Chromatin structure: a repeating unit of histones and DNA. Science 184:868-871

Korzus E, Rosenfeld MG, Mayford M (2004) CBP histone acetyltransferase activity is a critical component of memory consolidation. Neuron 42:961-972

Kouzarides T (2007) Chromatin modifications and their function. Cell 128:693-705

Kraft M, Cirstea IC, Voss AK, Thomas T, Goehring I, Sheikh BN, Gordon L, Scott H, Smyth GK, Ahmadian MR, Trautmann U, Zenker M, Tartaglia M, Ekici A, Reis A, Dorr HG, Rauch A, Thiel CT (2011) Disruption of the histone acetyltransferase MYST4 leads to a Noonan syndrome-like phenotype and hyperactivated MAPK signaling in humans and mice. J Clin Invest 121:34793491

Kueh AJ, Dixon MP, Voss AK, Thomas T (2011) HBO1 is required for H3K14 acetylation and normal transcriptional activity during embryonic development. Molecular and cellular biology 31:845-860

Kundu TK, Wang Z, Roeder RG (1999) Human TFIIIC relieves chromatin-mediated repression of RNA polymerase III transcription and contains an intrinsic histone acetyltransferase activity. Molecular and cellular biology 19:1605-1615

Kuo MH, Brownell JE, Sobel RE, Ranalli TA, Cook RG, Edmondson DG, Roth SY, Allis CD (1996) Transcription-linked acetylation by Gen5p of histones H3 and H4 at specific lysines. Nature 383:269-272

Lee KK, Workman JL (2007) Histone acetyltransferase complexes: one size doesn't fit all. Nature reviews Molecular cell biology 8:284-295 
Lee LV, Maranon E, Demaisip C, Peralta O, Borres-Icasiano R, Arancillo J, Rivera C, Munoz E, Tan K, Reyes MT (2002) The natural history of sex-linked recessive dystonia parkinsonism of Panay, Philippines (XDP). Parkinsonism \& related disorders 9:29-38

Lee S, Lee B, Lee JW, Lee SK (2009) Retinoid signaling and neurogenin2 function are coupled for the specification of spinal motor neurons through a chromatin modifier CBP. Neuron 62:641-654

Lemon B, Tjian R (2000) Orchestrated response: a symphony of transcription factors for gene control. Genes Dev 14:2551-2569

Lilja T, Heldring N, Hermanson O (2013) Like a rolling histone: epigenetic regulation of neural stem cells and brain development by factors controlling histone acetylation and methylation. Biochim Biophys Acta 1830:2354-2360

Lim DA, Suarez-Farinas M, Naef F, Hacker CR, Menn B, Takebayashi H, Magnasco M, Patil N, Alvarez-Buylla A (2006) In vivo transcriptional profile analysis reveals RNA splicing and chromatin remodeling as prominent processes for adult neurogenesis. Molecular and cellular neurosciences 31:131-148

Lin W, Zhang Z, Chen CH, Behringer RR, Dent SY (2008a) Proper Gen5 histone acetyltransferase expression is required for normal anteroposterior patterning of the mouse skeleton. Development, growth \& differentiation 50:321-330

Lin W, Zhang Z, Srajer G, Chen YC, Huang M, Phan HM, Dent SY (2008b) Proper expression of the Gcn5 histone acetyltransferase is required for neural tube closure in mouse embryos. Dev Dyn 237:928-940

Lois C, Garcia-Verdugo JM, Alvarez-Buylla A (1996) Chain migration of neuronal precursors. Science 271:978-981

Louet JF, O'Malley BW (2007) Coregulators in adipogenesis: what could we learn from the SRC (p160) coactivator family? Cell cycle 6:2448-2452

Luger K, Mader AW, Richmond RK, Sargent DF, Richmond TJ (1997) Crystal structure of the nucleosome core particle at 2.8 A resolution. Nature 389:251-260

Lundblad JR, Kwok RP, Laurance ME, Harter ML, Goodman RH (1995) Adenoviral E1A-associated protein p300 as a functional homologue of the transcriptional coactivator CBP. Nature 374:85-88

Lunyak VV, Atallah M (2011) Genomic relationship between SINE retrotransposons, Pol III-Pol II transcription, and chromatin organization: the journey from junk to 
jewel. Biochemistry and cell biology $=$ Biochimie et biologie cellulaire 89:495504

Makino S, Kaji R, Ando S, Tomizawa M, Yasuno K, Goto S, Matsumoto S, Tabuena MD, Maranon E, Dantes M, Lee LV, Ogasawara K, Tooyama I, Akatsu H, Nishimura M, Tamiya G (2007) Reduced neuron-specific expression of the TAF1 gene is associated with X-linked dystonia-parkinsonism. American journal of human genetics 80:393-406

Marmorstein R, Roth SY (2001) Histone acetyltransferases: function, structure, and catalysis. Curr Opin Genet Dev 11:155-161

Martinez E, Kundu TK, Fu J, Roeder RG (1998) A human SPT3-TAFII31-GCN5-L acetylase complex distinct from transcription factor IID. J Biol Chem 273:2378123785

Martinez-Cerdeno V, Lemen JM, Chan V, Wey A, Lin W, Dent SR, Knoepfler PS (2012) N-Myc and GCN5 regulate significantly overlapping transcriptional programs in neural stem cells. PloS one 7:e39456

Merson TD, Dixon MP, Collin C, Rietze RL, Bartlett PF, Thomas T, Voss AK (2006) The transcriptional coactivator Querkopf controls adult neurogenesis. J Neurosci 26:11359-11370

Mikkelsen TS, Ku M, Jaffe DB, Issac B, Lieberman E, Giannoukos G, Alvarez P, Brockman W, Kim TK, Koche RP, Lee W, Mendenhall E, O'Donovan A, Presser A, Russ C, Xie X, Meissner A, Wernig M, Jaenisch R, Nusbaum C, Lander ES, Bernstein BE (2007) Genome-wide maps of chromatin state in pluripotent and lineage-committed cells. Nature 448:553-560

Miller RW, Rubinstein JH (1995) Tumors in Rubinstein-Taybi syndrome. American journal of medical genetics 56:112-115

Misiti S, Koibuchi N, Bei M, Farsetti A, Chin WW (1999) Expression of steroid receptor coactivator-1 mRNA in the developing mouse embryo: a possible role in olfactory epithelium development. Endocrinology 140:1957-1960

Mizzen CA, Yang XJ, Kokubo T, Brownell JE, Bannister AJ, Owen-Hughes T, Workman J, Wang L, Berger SL, Kouzarides T, Nakatani Y, Allis CD (1996) The TAF(II)250 subunit of TFIID has histone acetyltransferase activity. Cell 87:12611270

Nagarajan P, Ge Z, Sirbu B, Doughty C, Agudelo Garcia PA, Schlederer M, Annunziato AT, Cortez D, Kenner L, Parthun MR (2013) Histone acetyl 
transferase 1 is essential for mammalian development, genome stability, and the processing of newly synthesized histones H3 and H4. PLoS genetics 9:e1003518

Nakashima K, Yanagisawa M, Arakawa H, Kimura N, Hisatsune T, Kawabata M, Miyazono K, Taga T (1999) Synergistic signaling in fetal brain by STAT3-Smad1 complex bridged by $\mathrm{p} 300$. Science $284: 479-482$

Nishihara E, Moriya T, Shinohara K (2007) Expression of steroid receptor coactivator-1 is elevated during neuronal differentiation of murine neural stem cells. Brain Res 1135:22-30

Nishihara E, Yoshida-Komiya H, Chan CS, Liao L, Davis RL, O'Malley BW, Xu J (2003) SRC-1 null mice exhibit moderate motor dysfunction and delayed development of cerebellar Purkinje cells. J Neurosci 23:213-222

North BJ, Verdin E (2004) Sirtuins: Sir2-related NAD-dependent protein deacetylases. Genome Biol 5:224

Nunan J, Small DH (2000) Regulation of APP cleavage by alpha-, beta- and gammasecretases. FEBS letters 483:6-10

Oelgeschlager M, Janknecht R, Krieg J, Schreek S, Luscher B (1996) Interaction of the co-activator CBP with Myb proteins: effects on Myb-specific transactivation and on the cooperativity with NF-M. EMBO J 15:2771-2780

Oike Y, Hata A, Mamiya T, Kaname T, Noda Y, Suzuki M, Yasue H, Nabeshima T, Araki K, Yamamura K (1999a) Truncated CBP protein leads to classical Rubinstein-Taybi syndrome phenotypes in mice: implications for a dominantnegative mechanism. Hum Mol Genet 8:387-396

Oike Y, Takakura N, Hata A, Kaname T, Akizuki M, Yamaguchi Y, Yasue H, Araki K, Yamamura K, Suda T (1999b) Mice homozygous for a truncated form of CREBbinding protein exhibit defects in hematopoiesis and vasculo-angiogenesis. Blood 93:2771-2779

Okada Y, Yamagata K, Hong K, Wakayama T, Zhang Y (2010) A role for the elongator complex in zygotic paternal genome demethylation. Nature 463:554-558

Papai G, Weil PA, Schultz P (2011) New insights into the function of transcription factor TFIID from recent structural studies. Curr Opin Genet Dev 21:219-224

Parthun MR (2007) Hat1: the emerging cellular roles of a type B histone acetyltransferase. Oncogene 26:5319-5328 
Parthun MR, Widom J, Gottschling DE (1996) The major cytoplasmic histone acetyltransferase in yeast: links to chromatin replication and histone metabolism. Cell 87:85-94

Pelletier N, Champagne N, Lim H, Yang XJ (2003) Expression, purification, and analysis of MOZ and MORF histone acetyltransferases. Methods 31:24-32

Pelletier N, Champagne N, Stifani S, Yang XJ (2002) MOZ and MORF histone acetyltransferases interact with the Runt-domain transcription factor Runx2. Oncogene 21:2729-2740

Petrij F, Giles RH, Dauwerse HG, Saris JJ, Hennekam RC, Masuno M, Tommerup N, van Ommen GJ, Goodman RH, Peters DJ, et al. (1995) Rubinstein-Taybi syndrome caused by mutations in the transcriptional co-activator CBP. Nature 376:348-351

Pirooznia SK, Chiu K, Chan MT, Zimmerman JE, Elefant F (2012a) Epigenetic regulation of axonal growth of Drosophila pacemaker cells by histone acetyltransferase tip60 controls sleep. Genetics 192:1327-1345

Pirooznia SK, Sarthi J, Johnson AA, Toth MS, Chiu K, Koduri S, Elefant F (2012b) Tip60 HAT activity mediates APP induced lethality and apoptotic cell death in the CNS of a Drosophila Alzheimer's disease model. PloS one 7:e41776

Price D, Jarman AP, Mason JO, Kind PC (2011) Building Brains: An Introduction to Neural Development. Wiley-Blackwell

Reppert SM, Weaver DR (2002) Coordination of circadian timing in mammals. Nature 418:935-941

Rochefort C, Gheusi G, Vincent JD, Lledo PM (2002) Enriched odor exposure increases the number of newborn neurons in the adult olfactory bulb and improves odor memory. J Neurosci 22:2679-2689

Roelfsema JH, Peters DJ (2007) Rubinstein-Taybi syndrome: clinical and molecular overview. Expert reviews in molecular medicine 9:1-16

Roelfsema JH, White SJ, Ariyurek Y, Bartholdi D, Niedrist D, Papadia F, Bacino CA, den Dunnen JT, van Ommen GJ, Breuning MH, Hennekam RC, Peters DJ (2005) Genetic heterogeneity in Rubinstein-Taybi syndrome: mutations in both the CBP and EP300 genes cause disease. American journal of human genetics 76:572-580

Sako W, Morigaki R, Kaji R, Tooyama I, Okita S, Kitazato K, Nagahiro S, Graybiel AM, Goto S (2011) Identification and localization of a neuron-specific isoform of 
TAF1 in rat brain: implications for neuropathology of DYT3 dystonia. Neuroscience 189:100-107

Sapountzi V, Logan IR, Robson CN (2006) Cellular functions of TIP60. The international journal of biochemistry \& cell biology 38:1496-1509

Scott EK, Lee T, Luo L (2001) enok encodes a Drosophila putative histone acetyltransferase required for mushroom body neuroblast proliferation. Current biology : CB 11:99-104

Sheikh BN, Dixon MP, Thomas T, Voss AK (2012) Querkopf is a key marker of selfrenewal and multipotency of adult neural stem cells. Journal of cell science 125:295-309

Simpson CL, Lemmens R, Miskiewicz K, Broom WJ, Hansen VK, van Vught PW, Landers JE, Sapp P, Van Den Bosch L, Knight J, Neale BM, Turner MR, Veldink JH, Ophoff RA, Tripathi VB, Beleza A, Shah MN, Proitsi P, Van Hoecke A, Carmeliet P, Horvitz HR, Leigh PN, Shaw CE, van den Berg LH, Sham PC, Powell JF, Verstreken P, Brown RH, Jr., Robberecht W, Al-Chalabi A (2009) Variants of the elongator protein 3 (ELP3) gene are associated with motor neuron degeneration. Hum Mol Genet 18:472-481

Simpson MA, Deshpande C, Dafou D, Vissers LE, Woollard WJ, Holder SE, GillessenKaesbach G, Derks R, White SM, Cohen-Snuijf R, Kant SG, Hoefsloot LH, Reardon W, Brunner HG, Bongers EM, Trembath RC (2012) De novo mutations of the gene encoding the histone acetyltransferase KAT6B cause Genitopatellar syndrome. American journal of human genetics 90:290-294

Sims RJ, 3rd, Belotserkovskaya R, Reinberg D (2004) Elongation by RNA polymerase II: the short and long of it. Genes Dev 18:2437-2468

Slaugenhaupt SA, Blumenfeld A, Gill SP, Leyne M, Mull J, Cuajungco MP, Liebert CB, Chadwick B, Idelson M, Reznik L, Robbins C, Makalowska I, Brownstein M, Krappmann D, Scheidereit C, Maayan C, Axelrod FB, Gusella JF (2001) Tissuespecific expression of a splicing mutation in the IKBKAP gene causes familial dysautonomia. American journal of human genetics 68:598-605

Spencer TE, Jenster G, Burcin MM, Allis CD, Zhou J, Mizzen CA, McKenna NJ, Onate SA, Tsai SY, Tsai MJ, O'Malley BW (1997) Steroid receptor coactivator-1 is a histone acetyltransferase. Nature 389:194-198

Squatrito M, Gorrini C, Amati B (2006) Tip60 in DNA damage response and growth control: many tricks in one HAT. Trends in cell biology 16:433-442 
Sterner DE, Berger SL (2000) Acetylation of histones and transcription-related factors. Microbiol Mol Biol Rev 64:435-459

Stiles J, Jernigan TL (2010) The basics of brain development. Neuropsychology review 20:327-348

Strahl BD, Allis CD (2000) The language of covalent histone modifications. Nature 403:41-45

Suganuma T, Gutierrez JL, Li B, Florens L, Swanson SK, Washburn MP, Abmayr SM, Workman JL (2008) ATAC is a double histone acetyltransferase complex that stimulates nucleosome sliding. Nature structural \& molecular biology 15:364-372

Sun Y, Jiang X, Price BD (2010) Tip60: connecting chromatin to DNA damage signaling. Cell cycle 9:930-936

Swaab DF, Fliers E (1985) A sexually dimorphic nucleus in the human brain. Science 228:1112-1115

Szumiel I, Foray N (2011) Chromatin acetylation, beta-amyloid precursor protein and its binding partner FE65 in DNA double strand break repair. Acta biochimica Polonica 58:11-18

Taipale M, Rea S, Richter K, Vilar A, Lichter P, Imhof A, Akhtar A (2005) hMOF histone acetyltransferase is required for histone $\mathrm{H} 4$ lysine 16 acetylation in mammalian cells. Molecular and cellular biology 25:6798-6810

Tan M, Luo H, Lee S, Jin F, Yang JS, Montellier E, Buchou T, Cheng Z, Rousseaux S, Rajagopal N, Lu Z, Ye Z, Zhu Q, Wysocka J, Ye Y, Khochbin S, Ren B, Zhao Y (2011) Identification of 67 histone marks and histone lysine crotonylation as a new type of histone modification. Cell 146:1016-1028

Tanaka Y, Naruse I, Hongo T, Xu M, Nakahata T, Maekawa T, Ishii S (2000) Extensive brain hemorrhage and embryonic lethality in a mouse null mutant of CREBbinding protein. Mechanisms of development 95:133-145

Tanaka Y, Naruse I, Maekawa T, Masuya H, Shiroishi T, Ishii S (1997) Abnormal skeletal patterning in embryos lacking a single Cbp allele: a partial similarity with Rubinstein-Taybi syndrome. Proc Natl Acad Sci U S A 94:10215-10220

Taverna SD, Li H, Ruthenburg AJ, Allis CD, Patel DJ (2007) How chromatin-binding modules interpret histone modifications: lessons from professional pocket pickers. Nature structural \& molecular biology 14:1025-1040

Thomas T, Corcoran LM, Gugasyan R, Dixon MP, Brodnicki T, Nutt SL, Metcalf D, Voss AK (2006) Monocytic leukemia zinc finger protein is essential for the 
development of long-term reconstituting hematopoietic stem cells. Genes Dev 20:1175-1186

Thomas T, Dixon MP, Kueh AJ, Voss AK (2008) Mof (MYST1 or KAT8) is essential for progression of embryonic development past the blastocyst stage and required for normal chromatin architecture. Molecular and cellular biology 28:5093-5105

Thomas T, Voss AK (2007) The diverse biological roles of MYST histone acetyltransferase family proteins. Cell cycle 6:696-704

Thomas T, Voss AK, Chowdhury K, Gruss P (2000) Querkopf, a MYST family histone acetyltransferase, is required for normal cerebral cortex development. Development 127:2537-2548

Torchia J, Rose DW, Inostroza J, Kamei Y, Westin S, Glass CK, Rosenfeld MG (1997) The transcriptional co-activator $\mathrm{p} / \mathrm{CIP}$ binds CBP and mediates nuclear-receptor function. Nature 387:677-684

Tse C, Sera T, Wolffe AP, Hansen JC (1998) Disruption of higher-order folding by core histone acetylation dramatically enhances transcription of nucleosomal arrays by RNA polymerase III. Molecular and cellular biology 18:4629-4638

Tsukahara S (2009) Sex differences and the roles of sex steroids in apoptosis of sexually dimorphic nuclei of the preoptic area in postnatal rats. Journal of neuroendocrinology 21:370-376

Viosca J, Lopez-Atalaya JP, Olivares R, Eckner R, Barco A (2010) Syndromic features and mild cognitive impairment in mice with genetic reduction on p300 activity: Differential contribution of p300 and CBP to Rubinstein-Taybi syndrome etiology. Neurobiology of disease 37:186-194

Visel A, Blow MJ, Li Z, Zhang T, Akiyama JA, Holt A, Plajzer-Frick I, Shoukry M, Wright C, Chen F, Afzal V, Ren B, Rubin EM, Pennacchio LA (2009) ChIP-seq accurately predicts tissue-specific activity of enhancers. Nature 457:854-858

Vitaterna MH, King DP, Chang AM, Kornhauser JM, Lowrey PL, McDonald JD, Dove WF, Pinto LH, Turek FW, Takahashi JS (1994) Mutagenesis and mapping of a mouse gene, Clock, essential for circadian behavior. Science 264:719-725

Voegel JJ, Heine MJ, Tini M, Vivat V, Chambon P, Gronemeyer H (1998) The coactivator TIF2 contains three nuclear receptor-binding motifs and mediates transactivation through CBP binding-dependent and -independent pathways. EMBO J 17:507-519 
Voss AK, Collin C, Dixon MP, Thomas T (2009) Moz and retinoic acid coordinately regulate H3K9 acetylation, Hox gene expression, and segment identity. Developmental cell 17:674-686

Voss AK, Thomas T (2009) MYST family histone acetyltransferases take center stage in stem cells and development. Bioessays 31:1050-1061

Voss AK, Thomas T (2011) Concepts in Histone Acetyltransferase Biology. In: Craig JM, Wong NC (eds) Epigenetics - A Reference Manual. Caister Academic Press, Norfolk, UK

Voss AK, Vanyai HK, Collin C, Dixon MP, McLennan TS, Sheikh BN, Scambler P, Thomas T (2012) MOZ regulates the Tbx1 locus, and Moz mutation partially phenocopies DiGeorge syndrome. Developmental cell 23:652-663

Walfish PG, Yoganathan T, Yang YF, Hong H, Butt TR, Stallcup MR (1997) Yeast hormone response element assays detect and characterize GRIP1 coactivatordependent activation of transcription by thyroid and retinoid nuclear receptors. Proc Natl Acad Sci U S A 94:3697-3702

Wang J, Weaver IC, Gauthier-Fisher A, Wang H, He L, Yeomans J, Wondisford F, Kaplan DR, Miller FD (2010) CBP histone acetyltransferase activity regulates embryonic neural differentiation in the normal and Rubinstein-Taybi syndrome brain. Developmental cell 18:114-125

Wang YL, Faiola F, Xu M, Pan S, Martinez E (2008) Human ATAC Is a GCN5/PCAFcontaining acetylase complex with a novel NC2-like histone fold module that interacts with the TATA-binding protein. J Biol Chem 283:33808-33815

Wang Z, Zang C, Cui K, Schones DE, Barski A, Peng W, Zhao K (2009) Genome-wide mapping of HATs and HDACs reveals distinct functions in active and inactive genes. Cell 138:1019-1031

Wassarman DA, Sauer F (2001) TAF(II)250: a transcription toolbox. Journal of cell science 114:2895-2902

Weiskirchen R, Gressner AM (2000) The cysteine- and glycine-rich LIM domain protein CRP2 specifically interacts with a novel human protein (CRP2BP). Biochemical and biophysical research communications 274:655-663

Winkler GS, Kristjuhan A, Erdjument-Bromage H, Tempst P, Svejstrup JQ (2002) Elongator is a histone $\mathrm{H} 3$ and $\mathrm{H} 4$ acetyltransferase important for normal histone acetylation levels in vivo. Proc Natl Acad Sci U S A 99:3517-3522 
Wittschieben BO, Otero G, de Bizemont T, Fellows J, Erdjument-Bromage H, Ohba R, Li Y, Allis CD, Tempst P, Svejstrup JQ (1999) A novel histone acetyltransferase is an integral subunit of elongating RNA polymerase II holoenzyme. Molecular cell 4:123-128

Wood MA, Kaplan MP, Park A, Blanchard EJ, Oliveira AM, Lombardi TL, Abel T (2005) Transgenic mice expressing a truncated form of CREB-binding protein (CBP) exhibit deficits in hippocampal synaptic plasticity and memory storage. Learning \& memory 12:111-119

Xu J, Li Q (2003) Review of the in vivo functions of the p160 steroid receptor coactivator family. Molecular endocrinology 17:1681-1692

Xu J, Liao L, Ning G, Yoshida-Komiya H, Deng C, O'Malley BW (2000a) The steroid receptor coactivator SRC-3 (p/CIP/RAC3/AIB1/ACTR/TRAM-1) is required for normal growth, puberty, female reproductive function, and mammary gland development. Proc Natl Acad Sci U S A 97:6379-6384

Xu J, Qiu Y, DeMayo FJ, Tsai SY, Tsai MJ, O'Malley BW (1998) Partial hormone resistance in mice with disruption of the steroid receptor coactivator-1 (SRC-1) gene. Science 279:1922-1925

$\mathrm{Xu}$ J, Wu RC, O'Malley BW (2009) Normal and cancer-related functions of the p160 steroid receptor co-activator (SRC) family. Nature reviews Cancer 9:615-630

Xu W, Edmondson DG, Evrard YA, Wakamiya M, Behringer RR, Roth SY (2000b) Loss of Gcn512 leads to increased apoptosis and mesodermal defects during mouse development. Nature genetics 26:229-232

Yamauchi T, Yamauchi J, Kuwata T, Tamura T, Yamashita T, Bae N, Westphal H, Ozato K, Nakatani Y (2000) Distinct but overlapping roles of histone acetylase PCAF and of the closely related PCAF-B/GCN5 in mouse embryogenesis. Proc Natl Acad Sci U S A 97:11303-11306

Yang C, Shapiro LH, Rivera M, Kumar A, Brindle PK (1998) A role for CREB binding protein and p300 transcriptional coactivators in Ets-1 transactivation functions. Molecular and cellular biology 18:2218-2229

Yang XJ, Ogryzko VV, Nishikawa J, Howard BH, Nakatani Y (1996) A p300/CBPassociated factor that competes with the adenoviral oncoprotein E1A. Nature 382:319-324 
Yao TP, Ku G, Zhou N, Scully R, Livingston DM (1996) The nuclear hormone receptor coactivator SRC-1 is a specific target of p300. Proc Natl Acad Sci U S A 93:10626-10631

Yao TP, Oh SP, Fuchs M, Zhou ND, Ch'ng LE, Newsome D, Bronson RT, Li E, Livingston DM, Eckner R (1998) Gene dosage-dependent embryonic development and proliferation defects in mice lacking the transcriptional integrator p300. Cell 93:361-372

Yao YL, Yang WM (2011) Beyond histone and deacetylase: an overview of cytoplasmic histone deacetylases and their nonhistone substrates. Journal of biomedicine \& biotechnology 2011:146493

Zhang CL, Zou Y, He W, Gage FH, Evans RM (2008) A role for adult TLX-positive neural stem cells in learning and behaviour. Nature 451:1004-1007

Zhu X, Singh N, Donnelly C, Boimel P, Elefant F (2007) The cloning and characterization of the histone acetyltransferase human homolog Dmel\TIP60 in Drosophila melanogaster: DmellTIP60 is essential for multicellular development. Genetics 175:1229-1240

\section{Figures}

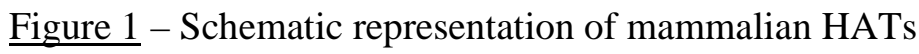

Mammalian HATs are organized into five families: the p300/CBP family, MYSTfamily, the GCN5-related HAT (GNAT) superfamily, the nuclear receptor co-activator (NCOA) family, and a set of transcription-initiation-related factors. The protein sizes correspond to the size of HATs in Mus musculus. Note that while NCOA2 shares sequence homology and an identical domain structure with its family, it has not been shown to have HAT activity as yet. It is only included in this schematic for completion. GTF3C1 and GTF3C4 are not shown as the regions responsible for their HAT activities are yet to be mapped.

aa - amino acids, AD - activation domain, bHLH - basic helix-loop-helix domain, CREB - cyclic adenosine monophosphate response element binding protein, HAT histone acetyltransferase, NR - nuclear receptor, PAS - Per-Arnt-Sim domain, PHD plant homeodomain, SAM - S-adenosylmethionine, SRC - steroid receptor coactivator.

* Note that the human homologue of QKF is referred to as KAT6B, and the Drosophila homologue as enok. 
Based on the NCBI database and Callebaut and Mornon 2012, Chinenov 2002, Doi et al. 2006, Dutnall et al. 1998, Kalkhoven 2004, Marmorstein and Roth 2001, Voss and Thomas 2011, Wassarman and Sauer 2001.

Figure 2 - Summary of HAT functions during neural development QKF is required for proliferation of neural progenitors during embryonic development, for maintaining the self-renewal and multipotency of adult NSCs, and promotes differentiation into the neuronal lineage. Similarly, GCN5 promotes proliferation of neuronal progenitors during embryonic development. CBP mediates differentiation of progenitors into astrocytes, oligodendrocytes and neurons. CBP family member p300 is likely to play a similar role, although this remains to be formally shown. ELP3 is required for the timely migration of neuronal precursors and for the maturation of neurites, while TFIIIC appears to inhibit premature neuron maturation. TIP60, at least in the Drosophila model, mediates axonal transport and is likely to be required for neuronal survival.

\section{Tables}

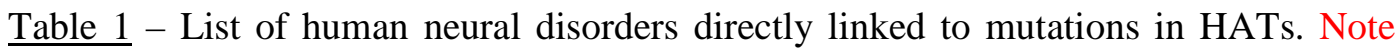
that the mouse homologue of KAT6B is QKF.

\begin{tabular}{|c|c|c|}
\hline Disease & Mutation in gene & Reference \\
\hline Rubinstein-Taybi syndrome & $C B P$ & Petrij et al., 1995 \\
\hline Rubinstein-Taybi syndrome & p300 & Roelfsema et al., 2005 \\
\hline Noonan syndrome & KАТбВ & Kraft et al., 2011 \\
\hline Genitopatellar syndrome & KAT6B & $\begin{array}{l}\text { Simpson et al., } 2012 \\
\text { Campeau et al., } 2012\end{array}$ \\
\hline $\begin{array}{l}\text { Say-Barber-Biescker-Young-Simpson } \\
\text { syndrome }\end{array}$ & KАT6B & $\begin{array}{l}\text { Clayton-Smith et al., } \\
2011\end{array}$ \\
\hline X-linked Dystonia-Parkinsonism & $T A F 1\left(T F_{I I} 250\right)$ & Makino et al., 2007 \\
\hline
\end{tabular}


p300/CBP family

p300

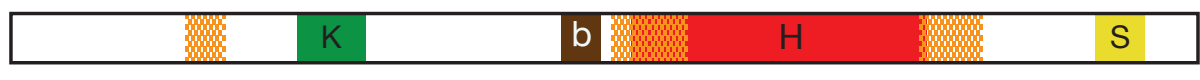
2412 aa

CBP

K
b S 2441 aa

K KIX (CREB interaction) domain cysteine-histidine rich regions
HAT domain

b bromodomain

S SRC interaction domain

MYST family

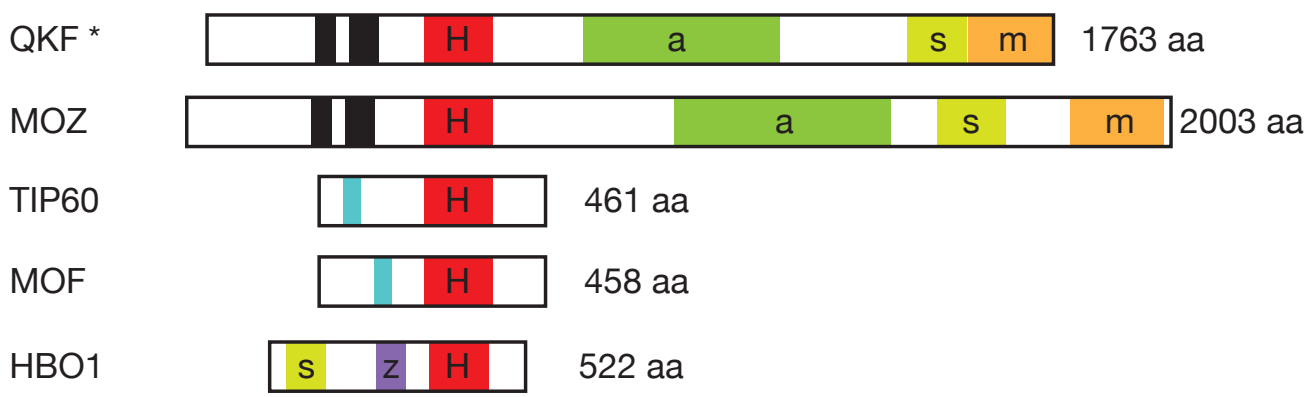

HAT domain PHD finger a acidic region $\mathrm{s}$ serine rich domain $\mathrm{m}$ metionine rich domain chromodomain zinc-finger

\section{GNAT superfamily}

\begin{tabular}{|c|c|c|}
\hline GCN5 & P & 829 aa \\
\hline PCAF & P & 813 aа \\
\hline CSRP2BP & w & 779 aа \\
\hline HAT1 & & 416 aa \\
\hline ELP3 & & 566 aа \\
\hline
\end{tabular}

H HAT domain
P PCAF homology domain
b bromodomain
W E3-ubiquitin ligase domain
w helix-winged-helix domain
PHD finger
$r$ radical SAM domain

NCOA family

\begin{tabular}{|c|c|c|c|c|c|c|}
\hline NCOA1 & $\mathrm{b}$ & $\mathrm{s}$ & & C & $\mathrm{H}$ & 1447 aа \\
\hline NCOA2 & b & $s$ & $E$ & $\mathrm{C}$ & Oa & 1393 aa \\
\hline NCOA3 & $\mathrm{b}$ & $\mathrm{s}$ & & $C$ & $\mathrm{H}$ & 1403 aa \\
\hline CLOCK & $\mathrm{b}$ & $\mathrm{s}$ & $\mathrm{H}$ & 5 aа & & \\
\hline
\end{tabular}

Transcription-related HATs

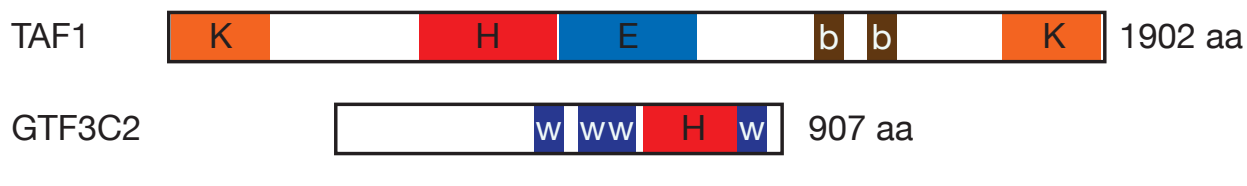

GTF3C1 and GTF3C4 not shown

AD2 \& HAT domain "If, AD2

C CREB interaction domain (AD1)

b bHLH domain

PAS domain

$S$ serine rich NR interaction

E E2F1 interaction domain

HAT domain

E1/E2 ubiquitin ligase domain

b bromodomain

$\mathrm{K}$ protein kinase domain

w WD40 repeats 


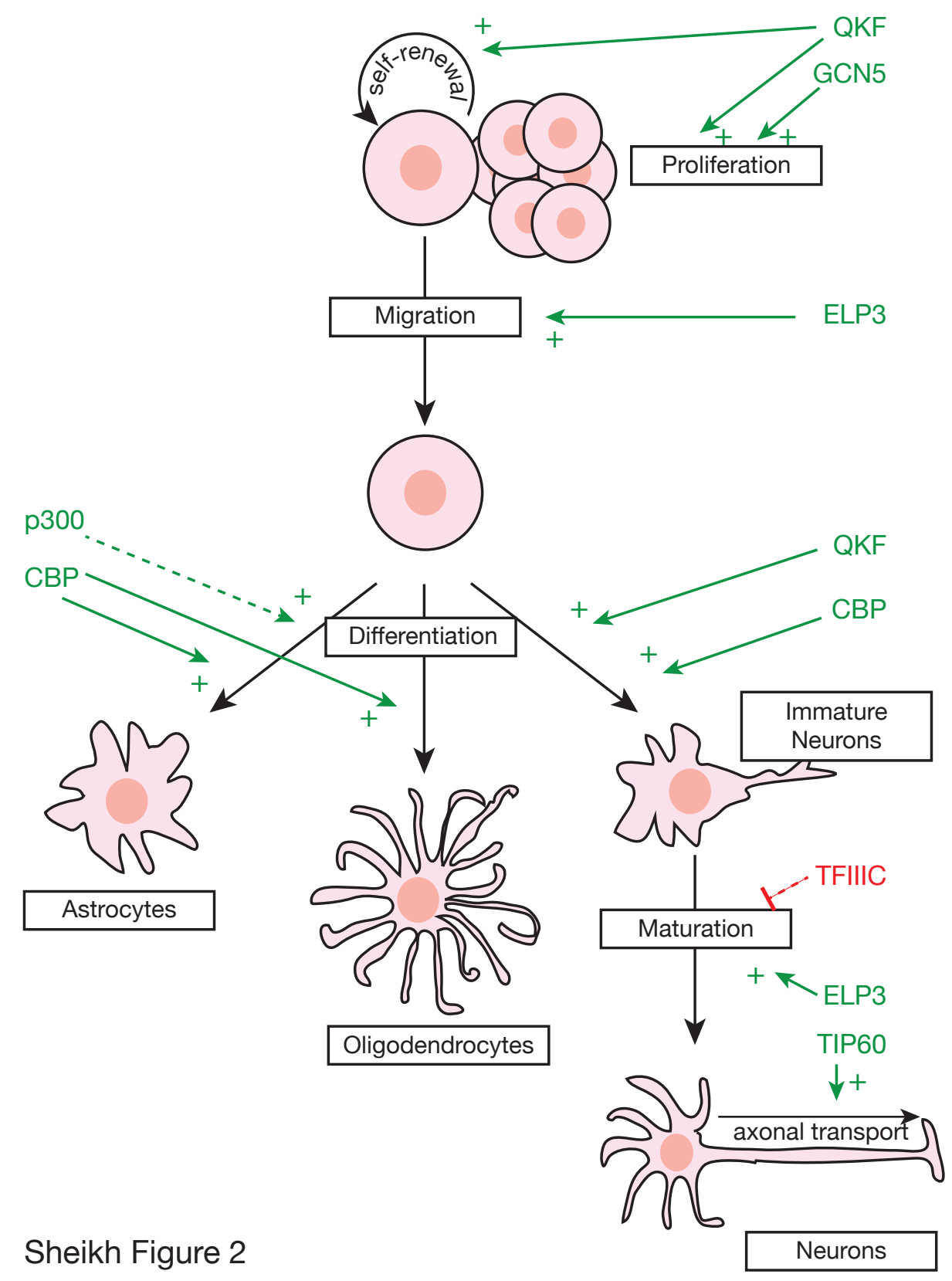

